\title{
Review Article \\ Parallel Aspects of the Microenvironment in Cancer and Autoimmune Disease
}

\author{
Michal A. Rahat and Jivan Shakya \\ Immunology Research Laboratory, Carmel Medical Center, and Ruth and Bruce Rappaport Faculty of Medicine, Technion, \\ 3436212 Haifa, Israel \\ Correspondence should be addressed to Michal A. Rahat; mrahat@netvision.net.il
}

Received 26 October 2015; Accepted 13 January 2016

Academic Editor: Simi Ali

Copyright (c) 2016 M. A. Rahat and J. Shakya. This is an open access article distributed under the Creative Commons Attribution License, which permits unrestricted use, distribution, and reproduction in any medium, provided the original work is properly cited.

\begin{abstract}
Cancer and autoimmune diseases are fundamentally different pathological conditions. In cancer, the immune response is suppressed and unable to eradicate the transformed self-cells, while in autoimmune diseases it is hyperactivated against a selfantigen, leading to tissue injury. Yet, mechanistically, similarities in the triggering of the immune responses can be observed. In this review, we highlight some parallel aspects of the microenvironment in cancer and autoimmune diseases, especially hypoxia, and the role of macrophages, neutrophils, and their interaction. Macrophages, owing to their plastic mode of activation, can generate a pro- or antitumoral microenvironment. Similarly, in autoimmune diseases, macrophages tip the Th1/Th2 balance via various effector cytokines. The contribution of neutrophils, an additional plastic innate immune cell population, to the microenvironment and disease progression is recently gaining more prominence in both cancer and autoimmune diseases, as they can secrete cytokines, chemokines, and reactive oxygen species (ROS), as well as acquire an enhanced ability to produce neutrophil extracellular traps (NETs) that are now considered important initiators of autoimmune diseases. Understanding the contribution of macrophages and neutrophils to the cancerous or autoimmune microenvironment, as well as the role their interaction and cooperation play, may help identify new targets and improve therapeutic strategies.
\end{abstract}

\section{Introduction}

The immune/inflammatory response is mostly beneficial to the host and is designed to combat and eradicate invading pathogens and then reestablish homeostasis. This universal response can also be activated in sterile inflammation, without any obvious infection, to repair excessive damage. The immune response is broadly categorized either as proinflammatory (consisting of Th1 and Thl7 cells, M1-activated macrophages, and proinflammatory mediators designed to kill pathogens or tumor cells) or as anti-inflammatory (dominated by Th2 cells, M2-activated macrophages, and antiinflammatory cytokines, designed to repair tissue damage). Of course, this approach is over simplistic, as more types of cell activation, including different types of regulatory $\mathrm{T}$ cells, macrophages, and B cells, are constantly being revealed.

In both cancer and autoimmune diseases an aberrant activation of the immune/inflammatory response leads to chronic diseases and accumulation of tissue damage. However, from an immunological standpoint, these two families of diseases are fundamentally different and even represent two opposite ways in which the immune system can go wrong. In cancer, the tumor cells are mostly unrecognized as antigens because a dominant anti-inflammatory response driven by the tumor cells suppresses any antitumoral immune response and promotes tumor progression and dissemination (immunosuppression). In fact, tumors are called wounds that do not heal, because the tumor hijacks the wound healing machinery and uses it to promote itself $[1,2]$. In contrast, in autoimmune diseases, self-tolerance is broken and the inflammatory response is activated in excess against the host tissue cells, which express autoantigens that are misrecognized and attacked by the immune system, gradually leading to permanent tissue damage.

Differences between cancer and autoimmunity are evident even at the cellular levels. In solid cancers, the immune infiltrate is composed mostly of macrophages, as well as $\mathrm{T}$ regulatory cells (Tregs), some T effector cells (CD8 cytotoxic $\mathrm{T}$ cells), and NK cells, whereas other cell types, such as neutrophils, dendritic cells, and fibroblasts, remain mostly 
at the tumor rims. In contrast, autoimmune diseases are usually dominated by Th1 and Th17 cells and their cytokine products IL-2, IFN $\gamma$, and IL-17 (in Th1 autoimmune diseases such as rheumatoid arthritis, RA, multiple sclerosis, MS, and Hashimoto thyroiditis, HT) or by Th2 cells and their anti-inflammatory cytokines IL-4, TGF $\beta$, and IL-10 (in Th2 autoimmune diseases such as systemic lupus erythematosus, SLE, systemic or local sclerosis, SSc, or scleroderma). Relative to healthy individuals, Tregs are partially impaired in autoimmune patients, partly explaining the broken tolerance which characterizes autoimmunity [3, 4].

Multiple factors play a role in determining the outcome of the aberrant inflammatory process, including the type of inflicted tissue or organ, the degree of tissue injury sustained, the type of cells activated, the amounts of protein and lipid mediators that are locally and systemically secreted by those cells, and the extent to which immune regulatory checkpoints are activated. Collectively, these comprise the microenvironment.

Despite the many differences and the opposite activation of the inflammatory process as a whole, some interesting similarities exist between cancer and autoimmunity, particularly in the way phagocytes are activated and in shared processes like angiogenesis. In this review we attempt to highlight some similarities in microenvironmental elements between cancerous and autoimmune diseases, focusing specifically on the roles macrophages and neutrophils play in these diseases and how these similarities provide potential new avenues for their treatment.

\section{A Causal Relationship between Cancer and Autoimmunity}

In recent years the paradigm that chronic inflammation contributes to carcinogenesis has gained much support, but the reciprocal idea that cancer may invoke autoimmunity remains controversial. The fact that cancer and autoimmune diseases may sometimes occur in the same individual suggests a possible link between these two different clinical conditions. In such people, it is likely that the inflammatory process drives both autoimmunity and malignancy. However, it is unclear whether the autoimmune disease preexists and its chronic inflammatory process leads to malignancy in some of the cases ("inflammation-induced cancer") or whether immune responses directed against tumor antigens eventually lead to autoimmune diseases ("tumor-induced autoimmunity").

2.1. Can an Autoimmune Disease Cause Cancer? Chronic inflammation has long been associated with increased risk of cancer. For example, patients with inflammatory bowel diseases (IBD, ulcerative colitis and Crohn's disease) have a 4-7-fold increased risk of developing colorectal cancer [13]. Autoimmune diseases are characterized as low-grade chronic inflammatory diseases that demonstrate leukocyte infiltration to the tissue, mostly by lymphocytes, and elevated levels of local and/or systemic inflammatory mediators, including cytokines, chemokines, and growth factors (e.g., IL-1 $\beta$, TNF $\alpha$, IL-6, CCL2/MCP-1, CXCL8/IL-8, and VEGF), reactive oxygen and nitrogen species (ROS, RNS), and autoantibodies [14]. The accumulation of these mediators results in slow and gradual tissue damage accompanied by somewhat increased angiogenesis and tissue remodeling, which is also called "smoldering inflammation" $[13,15]$. This creates the "extrinsic pathway" linking inflammation and cancer [13]. Mechanisms that explain the extrinsic pathway include the generation of ROS/RNS that can cause DNA damage, the induction of the activation-induced cytidine deaminase (AID) by proinflammatory cytokines that results in accumulation of nucleotide alterations and increased genetic instability, and the role that key inflammatory transcription factors (e.g., NF- $\kappa$ B and STAT3) play by inducing inflammatory cytokines and chemokines (e.g., IFN $\gamma, \operatorname{IFN} \alpha$, TNF $\alpha$, and IL-17), as well as key cell cycle and survival proteins (e.g., $\mathrm{Bcl} 2$ family members, cyclin D, cIAPs, and cFLIP) [reviewed in $[13,16,17]]$. Thus, chronic autoimmune diseases may indeed predispose patients to cancer over time. Many of these mediators (but not all) are products of phagocytes, especially neutrophils and macrophages, which affect tissue cells and drive their genetic instability.

2.2. Can Cancer Lead to an Autoimmune Disease? An "intrinsic pathway" that takes place within tissue cells links cancer to inflammation, whereby genetic events that activate oncogenes or inhibit tumor suppressor genes may also lead to induction of inflammatory proteins. For example, EGFR activation may activate COX-2 through the activation of the transcription factors Sp1 and p38-mitogen-activated protein kinase (MAPK); the oncogene ras is involved in the induction of the chemokine IL-8/CXCL8; and PTEN mutations cause an upregulation of the transcription factor HIF-1, which, in turn, upregulates the chemokine receptor CXCR4 [summarized in [13]]. Mutated genes in tumors that elicit an immune response may also lead to initiation of an autoimmune disease; if the response is cross-reactive with the normal protein, the appropriate MHC haplotype is expressed, and the tissue specificity is correct. One example was found in patients with systemic lupus erythematosus (SLE) or Wegener's granulomatosis (WG) that were also diagnosed with cancer around the same time [18, 19], raising the question of which occurred first. A more detailed example is a group of scleroderma patients with increased risk of cancer that were shown to have developed autoantibodies to RNA polymerase III subunit (RPCI, encoded by the POL3RA locus), as opposed to other scleroderma patients with no cancer that had autoantibodies only to centromere B protein (CENTB) or topoisomerase-I [20, 21]. In these patients, both humoral and cellular specific immune responses were observed, suggesting that the mutations in the POLR3A gene, which are rare in human tumors, were the initiator event triggering an immune response.

\section{The Microenvironment in Cancer and Autoimmunity}

The microenvironment of inflamed tissues includes different cell types that secrete a myriad of mediators, including cytokines, chemokines, growth factors, lipid mediators, ROS 
and RNS, remodeling enzymes, and neuropeptides. These are derived from both tissue and stroma cells and orchestrate the recruitment of new cells into the inflammatory site, their interactions with each other, and their functions within the site. Although this occurs mostly locally within the tissue, these mediators may also exert systemic influences on remote organs, for example, at the premetastatic site in cancer or when autoimmunity spreads to several remote organs. Below, we discuss some aspects of the cancerous and autoimmune microenvironments that are common to both.

3.1. The Hypoxic Microenvironment. Low oxygen tensions (hypoxia) are observed in all inflamed tissues. Because different tissues exhibit a wide range of oxygen tensions, even under normal conditions, a functional definition determines that hypoxia results when the oxygen supply does not meet the oxygen demand of the cells [47]. Hypoxia stabilizes the hypoxia-inducible factors (HIFs), which are the master regulatory transcription factors that carry out the adaptation response of cells to hypoxia, including the shift to glycolysis, induction of angiogenesis, increased invasion of leukocytes, and immune suppression [reviewed in [4852]]. Upregulation of HIF- $1 \alpha$ induces angiogenesis and the shift to glycolysis, as HIF- $1 \alpha$ binds to the hypoxia response element (HRE) found in the promoters of genes such as VEGF and the glycolytic enzymes. The switch to anaerobic glycolysis increases lactate levels, causing cellular acidosis and increased production of ROS, and leading to lipid peroxidation, membranal damage, impaired activity of ion channels, and increased membrane permeability. This increases spillage of cellular content and causes tissue acidosis and damage [5254], which, in turn, recruit more leukocytes into the site and trigger inflammation. Hence, hypoxia and inflammation are interdependent, as chronic inflammation is accompanied by hypoxia and prolonged hypoxia leads to inflammation [55].

In cancer, the uncontrolled proliferation of tumor cells increases tumor mass, which becomes depleted of oxygen and nutrient supply as the tumor reaches a diameter of 2$3 \mathrm{~mm}$, because of the increased distance from blood vessels. Since hypoxia is a major drive for angiogenesis, new blood vessels are produced to increase reoxygenation, and so different oxygen tensions can be measured in different regions within the tumor (Table 1) [56]. Partial pressure of oxygen values below $5 \mathrm{mmHg}$ is measured in more than $50 \%$ of advanced solid tumors $[57,58]$. Tumor cells are characterized by enhanced glycolysis, even in normoxic conditions (the Warburg effect), and hypoxia further enhances the anaerobic metabolism. The byproduct of glycolysis is lactic acid, which is transported out of the tumor cell to the microenvironment to prevent cell death by intracellular acidosis. Thus, neighboring stroma cells, particularly macrophages, are exposed to increased levels of lactate, which is actively transported into them. Lactate contributes to macrophage polarization by stabilizing HIF- $1 \alpha$ and inducing expression of typical M2phenotype markers like VEGF and arginase-I (ARG-I) [59], so that tumor-associated macrophages (TAMs) sense the metabolic changes in tumor cells and respond to them in a proangiogenic manner [1].
In autoimmune diseases, the increased infiltration of leukocytes into the inflamed site increases the demand for oxygen beyond the available supply. Low oxygen tensions were reported in organs with an ongoing inflammatory autoimmune process, such as the synovia in RA patients [10] and the pancreas in diabetes [60]. Thus, many macrophages infiltrate the synovium of RA patients, where they encounter a profound hypoxic microenvironment, upregulate HIF$1 \alpha$, and mediate an angiogenic process that is necessary for the formation of the inflammatory pannus and leukocyte infiltration [51]. Likewise, migration of $\mathrm{T}$ cells and macrophages into the sclerotic lesions of MS patients generates a hypoxic microenvironment that drives secretion of proangiogenic factors, including VEGF, angiopoietins, and MMPs, and induces angiogenesis around the demyelinating plaques [61]. Increased serum lactate concentrations in MS patients correlate with disease activity score and reflect the hypoxic microenvironment [62]. The role of hypoxia and angiogenesis in diseases like systemic lupus erythematosus (SLE) is not clear, but it is known that about $50 \%$ of the patients suffer from anemia, which leads to tissue hypoxia and reduced oxygen delivery, especially, but not limited to, the pulmonary vascular beds [8]. Accordingly, elevated levels of proangiogenic factors, such as VEGF, FGF, PIGF, TNF $\alpha$, TGF $\beta$, and HGF, were found in the serum of SLE patients [63]. Vascular disease, chronic tissue hypoxia, and excessive fibrosis that affects the skin and internal organs are the hallmarks of systemic sclerosis (SSc, scleroderma). An imbalance between proangiogenic factors (e.g., VEGF, PDGF) and antiangiogenic factors (e.g., angiostatin, thrombospondin-1) leads to increased serum levels of VEGF in early stages of the disease and increased serum levels of angiostatin in the late stage of the disease $[64,65]$.

Thus, in both diseases local hypoxia initiates a change in cell metabolism and elevates tissue acidosis, contributing to macrophage polarization and most importantly promoting the angiogenic switch, which is necessary for both cell survival and disease progression. Therefore, hypoxia and angiogenesis, although in different measures (Table 1), are two features of the microenvironment common to both cancer and autoimmunity.

3.2. Macrophages. Monocytes migrate into tissues and differentiate into macrophages that perform multiple, sometimes opposing functions that are needed in tissues, such as patrolling and maintaining homeostasis, eradicating tumor cells and pathogens, initiating wound healing and tissue repair, and resolving inflammation. These tasks are carried out by secreting inflammatory mediators (e.g., cytokines, chemokines, lipid mediators, and ROS/RNS) or anti-inflammatory mediators (e.g., IL-10, TGF $\beta$, and $\mathrm{PGE}_{2}$ ), presenting antigens to $\mathrm{T}$ cells and eliciting an adaptive immune response, scavenging apoptotic cells or necrotic debris, and depositing matrix proteins. Macrophages cannot perform all these tasks simultaneously, but they exhibit enormous plasticity, as they can be activated in different ways and constantly shift between them, according to the conditions in the changing microenvironment $[66,67]$. This concept has been thoroughly reviewed before [68-74]. One 
TABLE 1: Hypoxia in the microenvironment.

\begin{tabular}{|c|c|c|c|c|}
\hline & Cancer tissue & RA (SF) & MS/EAE & SLE \\
\hline Hypoxia & $\begin{array}{c}\leq 5 \mathrm{mmHg}(70-80 \mu \mathrm{m} \text { from } \\
\text { vessel }) ; \\
\leq 0.5 \mathrm{mmHg}(\geq 150 \mu \mathrm{m} \text { from } \\
\text { vessel }) ;[5] \\
0-2.5 \mathrm{mmHg} \text { (breast } \\
\text { cancer) [6] }\end{array}$ & $18-24 \mathrm{mmHg}$ & 9-20 mmHg in EAE [7] & $\begin{array}{l}\text { Not directly } \\
\text { measured; } \\
\text { anemic hypoxia } \\
\text { reported [8] }\end{array}$ \\
\hline Normal tissue & $\begin{array}{c}\text { Range: } 25-72 \mathrm{mmHg} \\
\text { (depending on tissue) [9] }\end{array}$ & $40-70 \mathrm{mmHg}[10-12]$ & 35 mmHg [7] & \\
\hline
\end{tabular}

extreme activation mode is the classically or M1-activated macrophages, which are activated to kill pathogens and tumor cells and accordingly express MHC class II and costimulatory molecules, Fc receptors to enhance phagocytosis, and proinflammatory and cytotoxic mediators (e.g., NO, $\mathrm{TNF} \alpha$ ). On the opposite extreme are the alternatively or M2-activated macrophages, which enhance wound healing and angiogenesis by expressing scavenger receptors (e.g., MARCO, CD206) and anti-inflammatory mediators (e.g., IL-10, TGF $\beta$, and $\mathrm{PGE}_{2}$ ), growth factors (e.g., VEGF), and matrix proteins. The hallmark of this type of activation is the high expression of arginase-I (ARG-I), which produces L-ornithine, the precursor for collagen synthesis, and polyamines that act as proliferative signals of cells. Another more refined approach further distinguishes between M2a, $\mathrm{M} 2 \mathrm{~b}$, and $\mathrm{M} 2 \mathrm{c}$ macrophages, where $\mathrm{M} 2 \mathrm{a}$ are fibrotic, $\mathrm{M} 2 \mathrm{~b}$ are immune regulators and produce IL- $1 \beta$, IL- 6 , and TNF $\alpha$, and $\mathrm{M} 2 \mathrm{c}$ are anti-inflammatory and are involved in tissue repair and remodeling [74]. In the continuum between the M1 and M2 options, macrophages can be activated in many forms of activation, which are very difficult to isolate and characterize. For example, regulatory macrophages are responsible for suppressing the Th1/M1 inflammatory response. Some of these cells are activated by Toll-like receptors (TLRs) ligands in combination with immune complexes, and some are activated by anti-inflammatory signals, such as adenosine or phagocytosed apoptotic cells $[68,72]$. Immature monocytes/macrophages, which compose the monocytic myeloidderived suppressor cells (M-MDSCs) population, also belong to regulatory macrophages and secrete IL-10 and TGF $\beta$ to help suppress Th1 and $\mathrm{CD}^{+} \mathrm{T}$ cells and recruit regulatory T cells [75-77]. MDSCs inhibit T effector cells by expressing both inducible nitric oxide synthase (iNOS) and ARG-I that compete for their mutual substrate L-arginine, leading to its depletion and reduced production of $\mathrm{CD} 3 \xi$ chain in the TCR receptor, and therefore decreased antigen-specific T cell responses and proliferation [78].

In cancer, macrophages play a dual role. The concept of immunoediting [79] suggests that, in early stages of tumor development, the immune system successfully surveys and eradicates tumor cells. Tumor cells that survive remain constantly under immune pressure, which helps to "sculpt" their phenotype into a more aggressive one, until finally, at the third stage, they escape immune recognition and become established. This concept describes a close relationship between tumor and immune cells, which is crucial for the determination of tumor fate and progression [80].
Furthermore, it suggests that the regulation of the immune response is critical to the fate of the tumor: if the response is mostly proinflammatory, the immune cells will turn against the tumor and eradicate its cells, whereas if the response is anti-inflammatory, the immune cells will provide mediators that are necessary for tumor growth and promote tumor progression. Much progress has been made in recent years in our understanding of how tumor cells actively tip the balance and maintain a favorable, anti-inflammatory, and immunosuppressive response through their interactions with macrophages.

The majority of the macrophages found in the tumor originate from monocytes that were recruited to the site. Circulating monocytes are heterogeneous and are generally divided into at least two subsets: a major subset of classical monocytes (Ly6C ${ }^{+}$in murine and $\mathrm{CD} 14^{++} \mathrm{CD}_{16}^{-}$in human) and a minor subset of nonclassical monocytes (Ly6C ${ }^{-}$in murine and $\mathrm{CD} 14^{+} \mathrm{CD} 16^{+}$in human). There is currently controversy as to the role of different monocytes subsets in tumor progression. It has been suggested that nonclassical monocytes are preferentially recruited into the primary tumor, and classical monocytes are recruited more to the metastatic sites [81]. In contrast, other studies show that nonclassical patrolling monocytes have a role in preventing metastatic spread [82]. Furthermore, other methods of monocytes classification, based on different markers, are possible, although not yet common. For example, classifying monocytes according to their Tie-2 expression may be very relevant in cancer, as those monocytes are recruited into the tumor and have a profound and strong proangiogenic activity that is critical for tumor progression $[83,84]$. This remains for now a subject of great interest.

Macrophages make up the major inflammatory cell population within tumors (Table 2), as they can infiltrate deep into the hypoxic microenvironment, unlike other leukocytes [85]. Several macrophage subsets have been found located in different regions of the tumor [86]. Tumor-associated macrophages (TAMs) are responsible for supporting tumor growth and dissemination. This is achieved by secreting IL-10 and TGF $\beta$ which inhibit adaptive immune responses, VEGF, and other proangiogenic factors that promote angiogenesis, growth factors such as EGF that are necessary for the tumor cell viability, and matrix remodeling enzymes such as matrix metalloproteinases (MMPs) that enable cellular motility. TAMs are activated in a manner approximating M2activation, and thus express ARG-I, produce matrix proteins, and secrete elevated levels of IL-10 and TGF $\beta$. Additional 
TABLE 2: Examples for the distribution of macrophages and neutrophils in different types of cancer and autoimmune diseases.

\begin{tabular}{|c|c|c|c|c|}
\hline Type of carcinoma & Localization & $\begin{array}{c}\text { Percentage } \\
(\%)\end{array}$ & Mice/human & Ref \\
\hline \multicolumn{5}{|c|}{ Macrophages in cancer } \\
\hline $\begin{array}{l}\text { Mammary gland } \\
\text { Gastrointestinal tumors } \\
\text { Diffuse large B-cell lymphoma } \\
\text { Non-small-cell lung cancer (NSCLC) }\end{array}$ & $\begin{array}{l}\text { Macrophages are found infiltrating all } \\
\text { areas of the tumors (including the } \\
\text { perinecroptic areas) } \\
\text { Many macrophages are found in the } \\
\text { stroma, in close contact with the cancer } \\
\text { cells }\end{array}$ & $\begin{array}{c}>40 \% \\
<30 \% \\
20 \% \\
15 \%-30 \%\end{array}$ & $\begin{array}{l}\text { Mice } \\
\text { Human } \\
\text { Human } \\
\text { Human }\end{array}$ & $\begin{array}{l}{[22]} \\
{[23]} \\
{[24]} \\
{[25,26]}\end{array}$ \\
\hline Prostate cancer & $\begin{array}{l}\text { In stroma and in close contact with } \\
\text { cancer cells }\end{array}$ & $10 \%-15 \%$ & Human & {$[27]$} \\
\hline Pancreatic cancer & Intratumoral and in the invasive front & $30-50 \%$ & Human & {$[28]$} \\
\hline Colon cancer & $\begin{array}{l}\text { Intratumoral, numbers increase with } \\
\text { tumor stage and grade }\end{array}$ & $25 \%-50 \%$ & Human & {$[29]$} \\
\hline $\begin{array}{l}\text { L929 Fibrosarcoma, B16 melanoma, LLC } \\
\text { lung carcinoma cells }\end{array}$ & Intratumoral & $23-51 \%$ & Mice & {$[30]$} \\
\hline \multicolumn{5}{|c|}{ Neutrophils in cancer } \\
\hline Lung cancer & Infiltrating the tumor & $8 \%$ & Human & {$[31]$} \\
\hline Clear cell renal cell carcinoma (RCC) & Intratumoral or near vessels & $14 \%$ & Human & [32] \\
\hline Mesothelioma, lung cancer & Intratumoral & $0.7-2.5 \%$ & Mice & {$[33]$} \\
\hline $\begin{array}{l}\text { L929 Fibrosarcoma, B16 melanoma, LLC } \\
\text { lung carcinoma cells }\end{array}$ & Intratumoral or near vessels & $3-8 \%$ & Mice & {$[30]$} \\
\hline \multicolumn{5}{|c|}{ Macrophages in autoimmune diseases } \\
\hline \multirow{4}{*}{ Rheumatoid arthritis (RA) } & Lining the synovial membrane & $41 \%$ & Human & {$[34]$} \\
\hline & Lining and infiltrating the synovium & $35-46 \%$ & Human & {$[35]$} \\
\hline & Lining and infiltrating the synovium & $17-36 \%$ & Human & {$[36]$} \\
\hline & Infiltrating the synovium & $26 \%$ & Human & {$[37]$} \\
\hline Multiple sclerosis (MS) & Infiltrating and at the rim of the lesion & $15-30 \%$ & Human & {$[38]$} \\
\hline Systemic lupus (SLE) & $\begin{array}{l}\text { Kidney: infiltrating all parenchyma, } \\
\text { found surrounding glomeruli and around } \\
\text { perivascular aggregate }\end{array}$ & $26 \%$ & Mice & {$[39]$} \\
\hline Systemic lupus (SLE) & Throughout the nephritic kidney & $4 \%$ & Mice & {$[40]$} \\
\hline Scleroderma & Skin & $23 \%$ & Rat & {$[41]$} \\
\hline Systemic sclerosis (SSc) & Superficial and deep dermis at early stages & $13 \%$ & Human & {$[42]$} \\
\hline \multicolumn{5}{|c|}{ Neutrophils in autoimmune diseases } \\
\hline \multirow{2}{*}{ Rheumatoid arthritis (RA) } & Lining and infiltrating the synovium & $8-15 \%$ & Human & {$[35]$} \\
\hline & Infiltrating the synovium & $4.5-7 \%$ & Human & [37] \\
\hline $\begin{array}{l}\text { Experimental autoimmune } \\
\text { encephalomyelitis (EAE) }\end{array}$ & $\begin{array}{l}\text { Within brain lesions } \\
\text { In the spinal cord }\end{array}$ & $\begin{array}{l}0.4-3 \% \\
8 \%\end{array}$ & Mice & {$[43-45]$} \\
\hline Systemic lupus (SLE, juvenile) & $\begin{array}{l}\mathrm{CD} 15^{+} \text {low density granulocytes in } \\
\text { circulation }\end{array}$ & $10 \%$ & Human & {$[46]$} \\
\hline
\end{tabular}

forms of macrophage activation in tumors include the Tieexpressing monocytes (TEMs), which are strongly proangiogenic and reside close to blood vessels [87] and MDSCs. MDSCs infiltrate the tumors and expand proportionally to the tumor burden $[70,72,84]$. TAMs, TEMs, and MDSCs are all obligatory components of the tumor microenvironment and share many similar markers and functions (especially TAMs and MDSCs), so it is very difficult to distinguish between them or to isolate them for in vitro studies.

Several microenvironmental conditions ensure that macrophages in tumors are activated in a way approximating
M2-activation. First, the tumor cells secrete soluble mediators, such as M-CSF/CSF-1, VEGF, and TGF $\beta$, which recruit macrophages to the tumor and maintain their viability, while polarizing them towards M2-activation [8890]. Second, the hypoxic microenvironment can shift even M1-activated macrophages towards M2-activation, utilizing multiple transcriptional and posttranscriptional mechanisms [48, 91-93]. Lastly, in a process called efferocytosis, macrophages engulf apoptotic cells, particularly apoptotic neutrophils (that were recruited to the tumor, secreted their content, and died by apoptosis; see Section 3.3), and 
this triggers M2-activation to promote angiogenesis, wound healing, and tissue remodeling [94]. Once M2 activated, these macrophages enhance their secretion of TGF $\beta$ and IL-10, thus further immunosuppressing M1-activated macrophages in their vicinity. In contrast, macrophages that phagocytose tumor cells undergoing secondary necrosis, which release danger-associated molecular patterns (DAMPs) such as HMGB1, are M1-activated, lead to increased secretion of inflammatory cytokines (TNF $\alpha$, IL-1 $\beta$, and IL-12), and promote Thl responses [95]. Thus, because of their plasticity, it is likely that, in the same tumor, some macrophages will be M1-triggered and most will be M2-activated, depending on their relative location within the tumor mass. This plasticity is now used in the treatment of cancer, as immunotherapy using monoclonal antibodies (e.g., anti-OX40, anti-EMMPRIN) was shown to modulate the microenvironment, reduce the levels of anti-inflammatory cytokines (e.g., TGF $\beta$ ), change the $\mathrm{T}$ cell infiltrate, and repolarize macrophages to become M1-activated, capable of killing tumor cells [96, 97]. Furthermore, drugs that alter TAMs activation were shown to enhance the effect of different immunotherapy approaches by changing the microenvironment [98]. However, the mechanisms that allow such manipulations are not entirely elucidated.

In contrast to cancer, the polarization state of macrophages in autoimmune diseases is poorly defined. Following the Th1/Th2 paradigm and extending it to the M1/M2 paradigm, one would expect to find M1 macrophages in Th1 autoimmune diseases such as RA, MS, and HT and M2 macrophages in Th2 autoimmune diseases such as SLE and scleroderma. However, the data is controversial. In one study, macrophages from the synovial fluid of RA patients expressed proinflammatory polarization markers (e.g., MMP12, CCR2), consistent with the elevated levels of proinflammatory cytokines detected in these patients' synovial fluids [123]. However, in another study, synovial fibroblasts were induced by TNF to secrete soluble factors that suppressed macrophage production of IFN $\beta$ and limited macrophage ability to respond to IFN $\beta$ by inhibiting Jak-STAT signaling, leading to decreased levels of M1chemokines such as CXCL9 and CXCL10 [124]. In MS patients, activated microglia in preactive and remyelinating lesions expressed a mixed phenotype with both M1 markers (CD74, CD40, and CD86) and M2 markers (CCL22 and CD209, but not CD206) [125], whereas, in a mouse model of experimental autoimmune encephalitis (EAE), inhibition of the Aurora kinase blocked disease development and shifted macrophage phenotype from M1 to M2 [126]. In SLE, the contribution of macrophages to disease pathogenesis was hardly investigated. In a mouse model of SLE, generated by immunization with activated lymphocyte-derived DNA, macrophages infiltrating the nephritic tissues exhibited activation markers of $\mathrm{M} 2 \mathrm{~b}$ polarization $\left(\mathrm{MHCII}^{\text {high }} \mathrm{CD} 86^{+} \mathrm{IL}-\right.$ $10^{\text {high }}$ IL-12 ${ }^{\text {low }}$ ) [127]. However, much evidence points to a possible mixed activation of macrophages in SLE, which includes both M1 and M2b polarized macrophages. For example, high levels of proinflammatory cytokines (e.g., $\mathrm{TNF} \alpha, \mathrm{GM}-\mathrm{CSF}, \mathrm{IFN} \gamma, \mathrm{CCL} 2$, and CXCL10) are found in serum of SLE patients, alongside high levels of IL-10 and IL-6 [128]. Both systemic and localized sclerosis (scleroderma) are autoimmune diseases manifested by vascular injury and progressive fibrosis of the skin, lung, and internal organs. The cytokine balance in these conditions is shifted towards Th2 cytokines, such as TGF $\beta$, PDGF, IL4, and IL-13. Accordingly, macrophages are M2-polarized with high expression of the CD206 marker [129]. Interestingly, this shift towards M2 was shown to be mediated by the enzyme $\mathrm{N}$-acetylglucosaminyltransferase-V (GnT-V) that glycosylates surface proteins, as mice with deficiency in the gene $\left(\mathrm{MGAT}^{-/-}\right)$were resistant to bleomycin-induced scleroderma and showed decreased M2-activation of cutaneous macrophages, with a similar total count of macrophages as the wild type mice [130].

The role of macrophages in cancer diseases has been investigated in depth, whereas their role in autoimmune diseases merits more research. The plasticity of macrophages and their ability to respond to changing conditions suggest that their polarization in vivo is difficult to assess. Unlike the defined in vitro stimulus, mixed signals in the complex microenvironment in vivo may result in different subpopulations of macrophages exhibiting different polarization and different functions. It is, therefore, important to precisely define the conditions in the microenvironment in each disease and to understand how these change over time in different parts of a tumor, in different organs, and in different stages of disease development. Furthermore, the mixed polarization of macrophages that is observed in vivo can be the result of intermediate transitioning from one polarization to another, or a result of a complex tissue structure that includes niches or even microniches that exhibit small nuances in the microenvironment. It is also important to remember that although most macrophages are recruited from the circulation during inflammation, some macrophages are resident in the tissue. At present, the specific role of tissue resident macrophages within the tumoral or autoimmune microenvironment is not well understood, mostly because of our current inability to distinguish them from recruited monocytes and due to their scarcity within the microenvironment. This is further complicated by the fact that, in some tissues, such as the intestine and heart, resident macrophages are gradually replaced by monocytederived macrophages $[131,132]$, whereas, in the brain, resident microglia are long-lived and can proliferate to maintain their numbers independently of monocyte infiltration [133]. The question whether these resident macrophages have different roles than the infiltrating monocyte-derive macrophages remains unresolved, but at least, in the murine model of EAE, microglia seem to be activated in early stages of disease development, supporting this premise [133]. Lastly, a new field of study of the trained innate immunity now demonstrates how innate immune cells may acquire a memory through epigenetic reprograming [134]. The significance of this subject to the activation of macrophages awaits further investigation and raises the question of how the history of the macrophages affects their ability to respond to the changing microenvironment and polarize correctly. 
3.3. Neutrophils. Neutrophils were viewed as cells that terminally differentiate in the circulation, migrate into tissue in response to inflammatory signals, degranulate in response to triggering, and die of apoptosis immediately after. However, recent findings challenge this concept and place neutrophils, together with macrophages, as cells that secrete a myriad of regulatory mediators that shape their immediate microenvironment, all depending on the diverse cell types they meet.

In cancer, and using an analogy to the M1- and M2activation modes of macrophages, neutrophils are now also categorized as antitumoral N1 and protumoral N2 tumorassociated neutrophils (TANs) [33]. Neutrophils make up a relatively small percentage of the tumor mass and are primarily found at the tumor rims and in nonnecrotic areas. They can infiltrate the tumor in small numbers (Table 1) and then are often found near blood vessels or in compact aggregations. However, changing the tumor microenvironment by blocking TGF $\beta$ signaling increases neutrophil infiltration and reduces tumor size [33]. TANs within the primary tumor are protumoral, as they secrete the proangiogenic factor $\mathrm{Bv} 8$, which is also responsible for myeloid cells recruitment, especially at early stages of malignancy [135], as well as the proangiogenic matrix metalloproteinase MMP-9, both in larger amounts than their cognate TAMs [30]. Furthermore, once TGF $\beta$ is blocked, a collaboration between TAMs and TANs is demonstrated, as TAMs produce neutrophil chemoattractants that recruit $\mathrm{CD}_{11 b^{+}} \mathrm{Ly}_{6 \mathrm{G}}{ }^{+}$neutrophils into the tumors [33]. Note that mature neutrophils and immature granulocytic MDSCs are practically indistinguishable, as they both express the same surface markers $\left(\mathrm{CD}_{11 b^{+}} \mathrm{Ly}_{6 \mathrm{G}}{ }^{+}\right)$, and it is yet unclear whether mature neutrophils arrive at the tumor from the circulation or whether immature MDSCs mature to N2 TANs within the tumor [33].

Neutrophils make up a much smaller fraction of the immune infiltrate in the tumors compared to macrophages, but their relative contribution is still unclear. For example, in some tumors, they may be the main producers of MMP9 and not the more abundant macrophages [30]. It is clear that the contribution of $\mathrm{CD} 1 \mathrm{~b}^{+} \mathrm{Grr}^{+}$granulocytic MDSCs to the formation of the premetastatic niche is significant. These granulocytic MDSCs (and not monocytic MDSCs) infiltrate the lung premetastatic niche well before tumor cells arrive there and secrete in situ large amounts of MMP-9, resulting in aberrant and leaky vasculature in the premetastatic lung. In addition, these G-MDSCs inhibit the secretion of IFN $\gamma$ by lung macrophages and increase the secretion of anti-inflammatory cytokines, such as IL-4, IL-5, and IL-10, indicating an immune suppression of the lung [136]. They can also secrete the neutrophil chemoattractants S100A9 and $\mathrm{S} 100 \mathrm{~A} 8$, as well as the proangiogenic Bv8. Interestingly, Bv8 also induces the migration of metastatic cells, suggesting that G-MDSCs direct the homing of metastatic tumor cells into the lung [137]. In contrast, other studies demonstrate that depletion of $\mathrm{Ly}_{6 \mathrm{G}}{ }^{+}$neutrophils does not change the size of the primary tumor but increases the lung metastatic burden, suggesting that tumor entrained neutrophils (TENs) at the premetastatic niche inhibit, rather than promote, metastasis [138]. Furthermore, adoptive transfer of such TENs significantly inhibited formation of lung metastatic foci, as they were highly cytotoxic to tumor cells. This cytotoxicity is triggered by the tumoral secretion of CCL2. However, neutrophils become cytotoxic only at the premetastatic lung and not at the primary tumor site where they are subjected to high levels of the local inhibitory effects of TGF $\beta$ [138]. This antitumoral effect of TENs was only temporary, and eventually they failed to inhibit metastasis. Thus, neutrophils display different functions at the primary tumor site and at the premetastatic niche, and within the metastatic niche their role changes over time.

Unlike macrophages, neutrophils can produce the proinflammatory cytokine IL-17, to mediate their involvement in cancer. IL-17 is mainly produced by either neutrophils or Th17 lymphocytic cells. High IL-17 levels or high frequency of cells producing IL-17 correlates with poor prognosis, whereas high Th17 cell frequencies were correlated with improved prognosis [139], suggesting that neutrophils might be the culprits. In fact, in different tumor types (e.g., head and neck, ovarian, endometrial, prostate, breast, lung, and colon carcinomas), IL-17 was mostly produced by neutrophils (66\% of the IL-17 producing cells in the tumor mass), whereas Th17 cells constituted only a small fraction of the immune infiltrate producing IL-17 (4\%) [140]. In contrast, other studies suggested that IL-17 was secreted by Th17 or $\gamma \delta$ T cells, which were responsible for neutrophil recruitment into the tumors. The recruited neutrophils, in turn, immunosuppressed CD8 ${ }^{+}$ cytotoxic $\mathrm{T}$ cells and promoted angiogenesis and metastasis $[141,142]$. Thus, although IL-17 is considered proinflammatory, its correlation with poor prognosis suggests that it also has protumoral roles. For example, IL-17 can increase tumor cell growth and migration [140, 141], induce IL-6 and CCL20 that recruit Th17 to the tumor site, and modulate gene expression of nontumor cells (including enhanced production of cytokines and chemokines, transcription factors, and antiapoptotic proteins), suggesting that neutrophils play an important role in tumors at an early stage [141].

In some autoimmune diseases, neutrophils are a major component of the immune infiltrate. For example, in RA, $90 \%$ of all leukocytes in the joint may be neutrophils [143], suggesting that they have a significant contribution to the pathogenesis of the disease. Although generally the role of neutrophils in autoimmune diseases has not been thoroughly investigated, their importance is now gradually gaining acceptance. Several possible mechanisms of action for neutrophils in autoimmune diseases have been suggested, as follows.

Neutrophils are phagocytes with a strong cytotoxic potential, and when activated in a proinflammatory manner (N1) they can enhance their secretion of proteases and ROS and, in an autoimmune context, inflict tissue damage. They also secrete chemokines that attract more neutrophils, macrophages, and other stroma cells into the inflamed site, thus amplifying the destructive effect in this context. In RA, migration of neutrophils to the joint is regulated by their enhanced expression of chemokine receptors (e.g., CCR2) that lead them towards elevated levels of CCL2 found in the synovial fluid (SF) [144]. Furthermore, IL-17 that is produced by neutrophils is an important mediator in arthritis, as IL-17 KO mice exhibit a clinical score less 
severe than wild type mice in the $\mathrm{K} / \mathrm{BxN}$ serum-induced arthritis model [145]. In MS patients, circulating neutrophils are primed compared to healthy controls and exhibit reduced apoptosis and enhanced expression of surface markers (e.g., TLR2, IL-8 receptor) [146]. Disruption of the blood brain barrier (BBB) in MS patients or in mice with EAE allows entry of leukocytes, including neutrophils, into the brain. Secretion of IL-17 by both Th17 and neutrophils helps to further disrupt the $\mathrm{BBB}$ and attract even more neutrophils and macrophages to the site of inflammation, especially at the preclinical stage before disease onset [43]. In patients with type I diabetes (T1D), the role of neutrophils remains controversial; however several observations indicate that circulating neutrophils are slightly reduced during the early stages of the disease and that they are accumulating at the exocrine pancreas in very small blood vessels or adjacent to acinar cells [147]. Neutrophils that are triggered by immune complexes are found in SF of RA patients, along with elevated levels of ROS [143]. In fact, neutrophils carrying the R620W polymorphism in the tyrosine phosphatase Lyp, which is highly expressed in neutrophils, exhibit enhanced migration and extravasation through endothelial cells, increased $\mathrm{Ca}^{2+}$ influx, and increased ROS production upon stimulation [148], demonstrating the importance of this polymorphism in the susceptibility to autoimmune diseases.

In another possible mechanism of action in autoimmune diseases, neutrophils have the ability to produce the enzyme peptidyl arginase deaminase-4 (PAD-4), which modifies the amino acid L-arginine into L-citrulline and is therefore involved in the generation of autoantibodies against citrullinated proteins found in both RA and MS patients in early stages $[149,150]$. Moreover, neutrophils can release chromatin extracellular traps (neutrophil extracellular traps, NETs) in a process termed "NETosis" (or "ETosis" when other cell types, such as mast cells, eosinophils, or macrophages, perform it, although less efficiently). These NETs are composed of chromatin fibrils, a combination of DNA and proteins, including histones (70\% of the proteins), HMGB1, neutrophil elastase (NE), myeloperoxidase (MPO), the peptide LL-37, and the hCAP18 fragment of cathelicidin. These proteins are recognized by immune cells (e.g., dendritic cells) as alarmins or danger-associated molecular pattern (DAMP) molecules when they are bound to DNA and spilled out of the cells. Citrulline is uncharged in neutral $\mathrm{pH}$, as opposed to arginine, and can change protein folding, structure, and function. Some proteins may naturally include citrulline (e.g., myelin basic protein, MBP, several histone proteins), whereas others undergo citrullination in the inflammatory site (e.g., fibrin and fibrinogen in RA joints). When these proteins are posttranslationally modified by citrullination, neoepitopes may be revealed that are no longer tolerated, leading to the production of proinflammatory cytokines such as TNF $\alpha$, IL6 , and IFN $\alpha$ [reviewed in [151]]. Low density granulocytes (LDG), a subset of immature neutrophils whose numbers increase in SLE patients, are particularly susceptible to NETosis, as they secrete IFN $\alpha$ [152]. NETosis is associated with the finding of antineutrophil cytoplasmic antibodies (ANCA) found in many SLE patients $[153,154]$ and is consistent with the finding of IFN $\alpha$ in the pancreas of T1D patients and the finding of IFN $\alpha$ and NETs in nonobese diabetic (NOD) mice that spontaneously develop T1D [reviewed in [147]]. In MS patients, higher serum levels of NETs were found [146].

Thus, neutrophils secrete many proinflammatory and cytotoxic mediators leading to the aggravation of the inflammatory response and culminating in gradually accumulating tissue damage, and they can cast NETs that lead to generation of autoantibodies, thus providing a hint to the etiology of autoimmune diseases. Both these mechanisms highlight neutrophils as significant and important cells in the generation of autoimmune diseases.

Neutrophils clearly play a large role in the microenvironment of both cancer and autoimmunity, but they are not as well understood as their "sibling" macrophages. Evidence suggests that they play a crucial role during early stages of diseases, but their role in later stages requires more investigation.

3.4. Macrophage-Neutrophil Cooperation. Macrophages and neutrophils show a high degree of overlap or redundancy as they secrete similar mediators, such as ROS, MMPs, cytokines, and chemokines. However, there are differences in the quantities produced and in gene expression. For example, both cell types secrete MMP-9 but in different quantities, and neutrophils, but not macrophages, can also secrete MMP-8; both phagocytes produce ROS, but neutrophils produce more hypochlorous acid; macrophages are by far better antigen presenting cells, whereas neutrophils excel in casting NETs. Both cell types are of myeloid origin and, therefore, have similar surface markers. Both types of cells exhibit similar plasticity, where the M1/N1 activation is geared to perform killing functions, whereas $\mathrm{M} 2 / \mathrm{N} 2$ activation is directed towards healing wounds and promoting angiogenesis.

There is now some evidence of cooperation between macrophages and neutrophils. Both cell types secrete cytokines and chemokines that recruit each other and enhance each other's proinflammatory activities, thus enhancing resolution of inflammation [155] (see Table 3 for details of some cytokines and chemokines in the microenvironment). Macrophages secrete the macrophage migration inhibitory factor (MIF) to enhance neutrophil survival and secretion of MMP-9, in the context of both cancer [156] and autoimmunity [157]. The manner by which neutrophils die profoundly affects macrophage polarization, and, therefore, the subsequent course of disease. In cancer, in the absence of activating signals, neutrophils have a short half-life of 6-18 hours in the circulation, before dying by apoptosis, and the process of their engulfment and processing by macrophages (efferocytosis) results in macrophage polarization towards M2-like activation and enhances immunosuppression [158]. Furthermore, neutrophils secretion of IL-17 helps to shift macrophage activation towards the $\mathrm{M} 2 \mathrm{~b}$ regulatory phenotype [159]. In contrast, in autoimmune diseases, presence of GMCSF and hypoxia can delay neutrophil apoptosis and increase their survival [143]. Moreover, in early RA patients, antiapoptotic cytokines (e.g., IL-4, GM-CSF, and G-CSF) that are found in their SF may lead to defects and low levels 
TABLE 3: Example concentrations of cytokines and chemokines in the microenvironment.

\begin{tabular}{|c|c|c|c|c|c|}
\hline & & Cancer (breast, pg/mL/mg) & $\mathrm{RA}\left(\mathrm{SF}^{\mathrm{b}}, \mathrm{pg} / \mathrm{mL}\right)$ & $\mathrm{MS} / \mathrm{EAE}\left(\mathrm{CSF}^{\mathrm{c}}, \mathrm{pg} / \mathrm{mL}\right)$ & SLE (serum, pg/mL) \\
\hline \multirow{2}{*}{ IL- $1 \beta$} & Disease & $2.7-3.5[99,100]$ & $\begin{array}{c}2.6[36] \\
9.26[101]\end{array}$ & $\begin{array}{l}0.02[102] \\
44.1[103]\end{array}$ & $\begin{array}{c}0.24[104] \\
11[105]\end{array}$ \\
\hline & Healthy/remission & $0[100]$ & $\begin{array}{c}0[36] \\
7.7[101] \\
\end{array}$ & $0[102]$ & $\begin{array}{c}0.1[104] \\
5[105]\end{array}$ \\
\hline \multirow[t]{2}{*}{ TNF $\alpha$} & Disease & $7.2[100]$ & $14.0[106]$ & $\begin{array}{c}1.85[102] \\
5.34[107] \\
9.0[108] \\
39.4[103]\end{array}$ & $\begin{array}{c}0.34[104] \\
1.24[109] \\
7.8-8.0[110,111] \\
44.76[105]\end{array}$ \\
\hline & Healthy/remission & $1.6[100]$ & $3.5[106]$ & $\begin{array}{l}0.93[102] \\
1.95[107] \\
\end{array}$ & $\begin{array}{c}0.1-2.2[104,109,111] \\
20[105] \\
\end{array}$ \\
\hline \multirow[t]{2}{*}{$\operatorname{IFN} \gamma$} & Disease & $27.6[100]$ & $0[36]$ & $\begin{array}{c}3.27[102] \\
5.7[107] \\
11.6[108]\end{array}$ & $\begin{array}{c}0.64[104] \\
6.5-7.05[109,110]\end{array}$ \\
\hline & Healthy/remission & $16.6[100]$ & $0-3.5[36,106]$ & $\begin{array}{c}0.2-0.52[102,108] \\
3.7[107]\end{array}$ & $1.3-11.7[104,109,110]$ \\
\hline \multirow{2}{*}{ IL-17A } & Disease & $0[100]$ & $\begin{array}{c}0[36] \\
12[112]\end{array}$ & $\begin{array}{c}6.93[102] \\
16.53[107]\end{array}$ & $97.42[109]$ \\
\hline & Healthy/remission & $0[100]$ & $\begin{array}{l}0[36] \\
4[112] \\
\end{array}$ & $\begin{array}{l}3.36[102] \\
13.7[107]\end{array}$ & 3.30 [109] \\
\hline \multirow[t]{2}{*}{ IL-6 } & Disease & $17.2[100]$ & $\begin{array}{l}1,253[36] \\
355[101]\end{array}$ & $\begin{array}{c}2.86[102] \\
6.02[107] \\
13.2[103,108]\end{array}$ & $\begin{array}{c}10.02[109] \\
20.8[110] \\
70.45[105]\end{array}$ \\
\hline & Healthy/remission & $1.2[100]$ & $\begin{array}{c}1,170[36] \\
87[101]\end{array}$ & $\begin{array}{c}2.5-12[102,108] \\
6.24[107] \\
\end{array}$ & $\begin{array}{c}0.5-2.18[109,110] \\
20[105]\end{array}$ \\
\hline \multirow{2}{*}{ TGF $\beta$} & Disease & $86.7[113]$ & $768[36]$ & 74.6 [107] & $42,990[109]$ \\
\hline & Healthy/remission & & $0[36]$ & 64 [107] & $82,710[109]$ \\
\hline \multirow{2}{*}{ IL-10 } & Disease & $0.3[100]$ & $16.2[36]$ & $\begin{array}{l}0.95[102] \\
4.34[107]\end{array}$ & $\begin{array}{c}1.2[111] \\
2.82[31,104] \\
9.78[109]\end{array}$ \\
\hline & Healthy/remission & $0[100]$ & $0[36]$ & $\begin{array}{c}0-0.63 \\
1.13[102] \\
0.38[107] \\
\end{array}$ & $0.54[104,109,111]$ \\
\hline \multirow{2}{*}{ CCL2/MCP-1 } & Disease & $121[100]$ & $25,000[114]$ & $\begin{array}{c}116.3[108] \\
574.4\end{array}$ & $136[115]$ \\
\hline & Healthy/remission & $1.9[100]$ & $920-2900$ [114] & $163-526[108,116]$ & $71[115]$ \\
\hline \multirow{2}{*}{ VEGF } & Disease & 1,148 [117] & $\begin{array}{l}1,100[118] \\
1,800[119]\end{array}$ & $\begin{array}{c}\text { Below the level of } \\
\text { detection [120] }\end{array}$ & $300.8[121]$ \\
\hline & Healthy/remission & 163 [117] & 700 [119] & $\begin{array}{c}\text { Below the level of } \\
\text { detection [120] }\end{array}$ & $124[121]$ \\
\hline \multirow[t]{2}{*}{ IL-4 } & Disease & $1.7-3.1[99,100]$ & $0[36]$ & $\begin{array}{c}0.17[102] \\
3.3[107] \\
8.6[116]\end{array}$ & $0.1-0.2[104,110]$ \\
\hline & Healthy/remission & $0[100]$ & $0[36]$ & $\begin{array}{c}0.03-0.1[102,116] \\
1.74[107]\end{array}$ & $\begin{array}{c}0 \\
1-0.3[104,110]\end{array}$ \\
\hline \multirow{2}{*}{ IL-8 } & Disease & $68[100]$ & $584[101]$ & $30-35[102,122]$ & 358 [111] \\
\hline & Healthy/remission & $1[100]$ & 451 [101] & $28-31[102,122]$ & 150 [111] \\
\hline \multirow[t]{2}{*}{ IL-12 } & Disease & $2.3[100]$ & $10.5[106]$ & $\begin{array}{c}1.44[102] \\
4.9[116]\end{array}$ & $1.0[104]$ \\
\hline & Healthy/remission & $1.4[100]$ & $6.1[106]$ & $0.56-1.4[102,116]$ & $0.18[104]$ \\
\hline
\end{tabular}

${ }^{\mathrm{a}}$ Measured in tumor extracts.

${ }^{b}$ Measured in the synovial fluid (SF).

${ }^{\mathrm{c}}$ Measured in the cerebrospinal fluid (CSF). 
of apoptotic death in neutrophils, suggesting that their engulfment by macrophages after secondary necrosis elicits a proinflammatory response.

This evidence suggests that macrophages and neutrophils communicate with each other and cooperate to regulate the microenvironment, explaining why both cell types seem to play similar roles in clinical settings. It has even been shown that when macrophages are depleted, or even change their activation mode, neutrophils gain the ability to infiltrate a tumor instead [98]. Therefore, myeloid cells and molecules that mediate their cooperation become new attractive targets for cancer immunotherapy. However, many questions that merit further investigation remain unanswered. For example, what factor(s) direct the tumor microenvironment, so that M2-TAMs become the dominant cellular component, rather than N2 TANs? Can macrophages compensate for the lack of neutrophils, or are neutrophils necessary for tumor growth, despite their being such a small percentage of the tumor mass? To what extent is this cooperation between macrophages and neutrophils necessary for tumor progression or for the development of the metastatic niche? And finally, is there a direct interaction between these two cell types, and if so, what protein(s) mediate it? Similarly, various interesting possibilities exist for the study of the role macrophages-neutrophils interactions play in autoimmune diseases.

3.5. Autoantibodies. Antibodies are effector molecules that specifically bind to their antigens and thus tag the cell for destruction either via complement fixation or via other effector cells (e.g., macrophages, NK cells) that have the appropriate $\mathrm{Fc}$ receptor. The binding of antibodies can also promote or inhibit cell signaling and activation. During early stages of an autoimmune disease, the process of NETosis exposes many citrullinated self-proteins to the immune system, and since the modification renders these proteins neoantigens, tolerance is broken and the immune system can generate autoantibodies and enhance epitope spreading, resulting in autoimmune responses $[149,151]$. Other posttranslational modifications (PTM), such as carbamylation and oxidation, can also generate neoantigens and autoantibodies [160]. The binding of these autoantibodies to their modified targets may drive tissue damage through their effector functions and contribute to the generation of autoimmune diseases [161], suggesting a causative role for the autoantibodies. However, it should be remembered that NETosis is a physiological and protective process (e.g., limiting invading pathogens) that does not necessarily lead to an autoimmune response. Additional factors (e.g., specific genetic background of an individual, specific polymorphism in genes related to NETosis, and defects in the mechanisms responsible for the clearance of NETs) must also exist to allow an autoimmune disease to develop [154].

In many autoimmune diseases autoantibodies can be found in the serum of patients and these may have critical role in the pathogenesis of these diseases through aberrant signaling of cells or through their destruction. In fact, autoantibodies can be considered a hallmark of autoimmune diseases and are therefore often used as biomarkers for disease progression. For example, presence of autoantibodies against insulin, GAD65, and IA-2 can confirm the diagnosis of type I diabetes (T1D) [147], and anti-dsDNA antibodies bind to resident kidney cells and trigger signaling that promotes inflammation and fibrosis in SLE [162]. Antinuclear antibodies (ANAs) are widely used as diagnostic biomarkers, and they have been shown to be involved in the pathogenesis of several autoimmune diseases, particularly systemic autoimmune diseases, as they form immune complexes with their target proteins and generate inflammation in many organs, like the kidney, lung, skin, brain, joints, and others [163]. Some ANAs are associated with specific diseases. For example, autoantibodies to double-stranded DNA and antihistones are associated with SLE, whereas anti-DNAtopoisomerase-I and anti-centromere protein B (CENTB) are linked to scleroderma [163].

Autoantibodies can be found in patients with inflammatory diseases that may ultimately progress into cancer, such as chronic hepatitis and liver cirrhosis, even in early, precancerous stages. Once cancer progresses, many autoantibodies can be found in different types of solid cancers, directed against over 100 tumor-associated antigens (TAAs), including autoantibodies to CA-125, chromogranin A, and plasminogen [164-166]. However, some of these autoantibodies overlap with autoantibodies found in patients with autoimmune diseases, such as different ANAs (e.g., antiSm, anti-CENTB), autoantibodies to double-stranded DNA, p53, and c-Myc $[167,168]$. Autoantibodies to citrullinated proteins were found significantly more frequently in the sera of diffuse large B-cell non-Hodgkin lymphoma patients than in healthy controls [169]. The presence of such autoantibodies in cancer may be explained by the increased necrotic death of tumor cells, combined with neutrophil-derived NETosis and proteolysis of spilled proteins that may reveal cryptic epitopes. However, the role these autoantibodies play in cancer is still undetermined. It is possible that such autoantibodies may confer partial protection from cancer by promoting tumor cell death through complement-dependent cytotoxicity (CDC) or macrophage-mediated antibody-mediated cell cytotoxicity (ADCC), at least in early stages of cancer development. This has been shown for anti-TPO and anti-Tg autoantibodies in patients with both Hashimoto's thyroiditis and papillary thyroid cancer [14]. Other protective effects, such as inhibition of protein activity or induction of cell cycle arrest, should also be investigated. However, it is likely that, in later stages of tumor growth, the immunosuppressive microenvironment hampers those effects. Clearly, the relevance of autoantibodies to tumor pathogenesis merits more investigation.

Antibodies are, therefore, components in the microenvironment of both autoimmune and cancerous diseases. Although they are known to be very powerful effector molecules, the pathogenic role of antibodies in these diseases, especially in cancer, remains not fully elucidated, and it is possible that lessons learnt in one clinical scenario will improve our understanding of the other. 


\section{Concluding Remarks}

We reviewed here several aspects of the microenvironment in two clinically and immunologically opposing diseases and showed that, despite their fundamental differences, there are some instructive parallels between them. For example, hypoxia and angiogenesis are a common denominator in both diseases, although oxygen tensions may be variable and not comparable per se. Likewise, the presence of autoantibodies is a similar feature, especially when autoantibodies against the same self-antigens are involved. In this respect, it is likely that research of these elements in the context of one disease will shed light on their role in a different disease.

Innate immunity, and specifically myeloid cells, has long been recognized as crucial for tumor progression and metastasis, whereas its role in autoimmune diseases is only beginning to be unfolded. The paradigm that autoimmune diseases are mediated exclusively by $\mathrm{B}$ and $\mathrm{T}$ cells of adaptive immunity is gradually shifting to one recognizing the vital role that myeloid cells play as drivers and regulators of the microenvironment and of autoimmune responses. The adaptive immune cells ( $\mathrm{T}$ and $\mathrm{B}$ lymphocytes) must be activated by antigen presenting cells, a process requiring the prolonged activation of both macrophages and neutrophils. In particular, after macrophages were recognized as cells with enormous plasticity that respond to and regulate a changing microenvironment, this concept has extended to recognize similar properties in neutrophils in both cancer and autoimmune diseases. In view of the chronicity of both cancer and autoimmune diseases, the paradigm that neutrophils are short-lived and fully differentiated cells now shifts to include the understanding that neutrophils can extend their survival according to conditions in the microenvironment. Indeed, the newly discovered involvement of neutrophils in both cancer and autoimmunity and the importance of the interactions between neutrophils and macrophages present a novel field of study, which will probably expand in the future.

Lastly, identifying the parallels in these two clinically opposing diseases may provide us with new targets and tools for therapy. For example, the ability of macrophages to home in on the hypoxic regions in tumors leads us to use these cells as vehicles to deliver gene therapy [170]. Amazing progress has been made in immunotherapy during the last few years, where different regulatory checkpoints and "go signals" are targeted in an attempt to change the microenvironment. In autoimmune diseases such as RA, anti-TNF biologics are now routinely administered and improve life quality for many patients, and, in cancer, we have recently witnessed the success of combined anti-CTLA4 and anti-PD-L1/PD-1 in the treatment of melanoma [171]. Targeting the process of leukocytes recruitment into inflamed sites is now gaining more success. Using CCR2 antagonists inhibited tumor growth and prevents metastasis $[81,172]$, as well as reducing inflammation and joint destruction in a murine model of adjuvant-induced arthritis [173]. Additional targets, such as the CSF-1 receptor kinase or CX3CL1, lead to macrophage depletion and greatly improved kidney pathologies in mouse models of nephritic lupus [174, 175]. Neutrophil recruitment can also be targeted by blocking CXCL8 or CXCL6 signaling with antibodies, and this approach has produced similar benefits in inhibiting tumor growth and metastasis [176, 177]. Other strategies that target the immunosuppressive microenvironment, specifically by targeting different steps in TGF $\beta$ signaling pathway, also show efficacy in reducing invasiveness, migration, and tumor size in murine models of breast [178, 179], glioma [180], and colon cancer [181]. This targeting of TGF $\beta$ pathway ameliorated immunosuppression and shifted the cellular composition within tumor microenvironment towards increased $\mathrm{CD} 8^{+} \mathrm{T}$ cells, macrophages, and NK cells [180].

These novel and promising immunotherapies can be further extended with novel targets, like anti-IL-6 receptor, anti-CD20, and many others that are already in the pipeline. By studying the parallels and differences between cancer and autoimmunity, other potential targets could be identified and appropriate strategies developed to achieve the desired outcome of treatment for cancer and autoimmune diseases.

\section{Conflict of Interests}

The authors declare that there is no conflict of interests regarding the publication of this paper.

\section{Authors' Contribution}

Michal A. Rahat drafted and wrote the paper. Jivan Shakya collected data and helped organize the paper. Both authors have given approval to the final version of the paper.

\section{Acknowledgments}

The authors are supported by the Israel Science Foundation (ISF, Grant no. 1392/14), the Kamin MAGNET directorate, Israel Ministry of Economy, and the Israel Cancer Foundation (ICA, Grant no. 20150048).

\section{References}

[1] V. Bronte, "Tumor cells hijack macrophages via lactic acid," Immunology and Cell Biology, vol. 92, pp. 647-649, 2014.

[2] H. F. Dvorak, “Tumors: wounds that do not heal-redux," Cancer Immunology Research, vol. 3, no. 1, pp. 1-11, 2015.

[3] A. B. Glick, A. Wodzinski, P. Fu, A. D. Levine, and D. N. Wald, "Impairment of regulatory T-Cell function in autoimmune thyroid disease," Thyroid, vol. 23, no. 7, pp. 871-878, 2013.

[4] B. Bolon, "Cellular and molecular mechanisms of autoimmune disease," Toxicologic Pathology, vol. 40, no. 2, pp. 216-229, 2012.

[5] G. Helmlinger, F. Yuan, M. Dellian, and R. K. Jain, "Interstitial $\mathrm{pH}$ and $\mathrm{pO} 2$ gradients in solid tumors in vivo: high-resolution measurements reveal a lack of correlation," Nature Medicine, vol. 3, no. 2, pp. 177-182, 1997.

[6] M. Molls, H. J. Feldmann, and J. Fuller, "Oxygenation of locally advanced recurrent rectal cancer, soft tissue sarcoma and breast cancer," Advances in Experimental Medicine and Biology, vol. 345, pp. 459-463, 1994.

[7] A. L. Davies, R. A. Desai, P. S. Bloomfield et al., "Neurological deficits caused by tissue hypoxia in neuroinflammatory disease," Annals of Neurology, vol. 74, no. 6, pp. 815-825, 2013. 
[8] K. J. Kim, I. W. Baek, C. H. Yoon, W. U. Kim, and C. S. Cho, "Anemic hypoxia is associated with increased pulmonary artery systolic pressure in patients with systemic lupus erythematosus," Arthritis Care \& Research, 2015.

[9] A. Carreau, B. E. Hafny-Rahbi, A. Matejuk, C. Grillon, and C. Kieda, "Why is the partial oxygen pressure of human tissues a crucial parameter? Small molecules and hypoxia," Journal of Cellular and Molecular Medicine, vol. 15, no. 6, pp. 1239-1253, 2011.

[10] M. Biniecka, E. Fox, W. Gao et al., "Hypoxia induces mitochondrial mutagenesis and dysfunction in inflammatory arthritis," Arthritis \& Rheumatism, vol. 63, no. 8, pp. 2172-2182, 2011.

[11] A. Kennedy, C. T. Ng, M. Biniecka et al., "Angiogenesis and blood vessel stability in inflammatory arthritis," Arthritis \& Rheumatism, vol. 62, no. 3, pp. 711-721, 2010.

[12] B. Muz, M. N. Khan, S. Kiriakidis, and E. M. Paleolog, "Hypoxia. The role of hypoxia and HIF-dependent signalling events in rheumatoid arthritis," Arthritis Research and Therapy, vol. 11, article 201, 2009.

[13] A. Del Prete, P. Allavena, G. Santoro, R. Fumarulo, M. M. Corsi, and A. Mantovani, "Molecular pathways in cancerrelated inflammation," Biochemia Medica, vol. 21, no. 3, pp. 264275, 2011.

[14] M. Ehlers and M. Schott, "Hashimoto's thyroiditis and papillary thyroid cancer: are they immunologically linked?" Trends in Endocrinology \& Metabolism, vol. 25, no. 12, pp. 656-664, 2014.

[15] F. Balkwill, K. A. Charles, and A. Mantovani, "Smoldering and polarized inflammation in the initiation and promotion of malignant disease," Cancer Cell, vol. 7, no. 3, pp. 211-217, 2005.

[16] A. L. Franks and J. E. Slansky, "Multiple associations between a broad spectrum of autoimmune diseases, chronic inflammatory diseases and cancer," Anticancer Research, vol. 32, no. 4, pp. 11191136, 2012.

[17] F. Colotta, P. Allavena, A. Sica, C. Garlanda, and A. Mantovani, "Cancer-related inflammation, the seventh hallmark of cancer: links to genetic instability," Carcinogenesis, vol. 30, no. 7, pp. 1073-1081, 2009.

[18] S. Bernatsky, J. F. Boivin, L. Joseph et al., "An international cohort study of cancer in systemic lupus erythematosus," Arthritis \& Rheumatism, vol. 52, no. 5, pp. 1481-1490, 2005.

[19] E. Tatsis, E. Reinhold-Keller, K. Steindorf, A. C. Feller, and W. L. Gross, "Wegener's granulomatosis associated with renal cell carcinoma," Arthritis and Rheumatism, vol. 42, no. 4, pp. 751756, 1999.

[20] A. A. Shah and A. Rosen, "Cancer and systemic sclerosis: novel insights into pathogenesis and clinical implications," Current Opinion in Rheumatology, vol. 23, no. 6, pp. 530-535, 2011.

[21] C. G. Joseph, E. Darrah, A. A. Shah et al., "Association of the autoimmune disease scleroderma with an immunologic response to cancer," Science, vol. 343, no. 6167, pp. 152-157, 2014.

[22] K. Movahedi, D. Laoui, C. Gysemans et al., "Different tumor microenvironments contain functionally distinct subsets of macrophages derived from Ly6C(high) monocytes," Cancer Research, vol. 70, no. 14, pp. 5728-5739, 2010.

[23] S. Cameron, M. Gieselmann, M. Blaschke, G. Ramadori, and L. Füzesi, "Immune cells in primary and metastatic gastrointestinal stromal tumors (GIST)," International Journal of Clinical and Experimental Pathology, vol. 7, no. 7, pp. 3563-3579, 2014.

[24] W. Kazmierczak, A. Lazar, R. Tomaszewska et al., "Analysis of the intensity of immune cell infiltration and immunoreactivity of RCAS1 in diffuse large B-cell lymphoma of the palatine tonsil and its microenvironment," Cell and Tissue Research, vol. 361, no. 3, pp. 823-831, 2015.

[25] F. Dai, L. Liu, G. Che et al., "The number and microlocalization of tumor-associated immune cells are associated with patient's survival time in non-small cell lung cancer," BMC Cancer, vol. 10, article 220, 2010.

[26] J. Ma, L. Liu, G. Che, N. Yu, F. Dai, and Z. You, "The M1 form of tumor-associated macrophages in non-small cell lung cancer is positively associated with survival time," BMC Cancer, vol. 10, article 112, 2010.

[27] S. Shimura, G. Yang, S. Ebara, T. M. Wheeler, A. Frolov, and T. C. Thompson, "Reduced infiltration of tumor-associated macrophages in human prostate cancer: association with cancer progression," Cancer Research, vol. 60, no. 20, pp. 5857-5861, 2000.

[28] H. Kurahara, H. Shinchi, Y. Mataki et al., "Significance of M2polarized tumor-associated macrophage in pancreatic cancer," Journal of Surgical Research, vol. 167, no. 2, pp. e211-e219, 2011.

[29] Q. Zhou, R.-Q. Peng, X.-J. Wu et al., "The density of macrophages in the invasive front is inversely correlated to liver metastasis in colon cancer," Journal of Translational Medicine, vol. 8, article 13, 2010.

[30] E. I. Deryugina, E. Zajac, A. Juncker-Jensen, T. A. Kupriyanova, L. Welter, and J. P. Quigley, "Tissue-infiltrating neutrophils constitute the major in vivo source of angiogenesis-inducing MMP-9 in the tumor microenvironment," Neoplasia, vol. 16, no. 10, pp. 771-788, 2014.

[31] E. B. Eruslanov, P. S. Bhojnagarwala, J. G. Quatromoni et al., "Tumor-associated neutrophils stimulate $\mathrm{T}$ cell responses in early-stage human lung cancer," The Journal of Clinical Investigation, vol. 124, no. 12, pp. 5466-5480, 2014.

[32] H. K. Jensen, F. Donskov, N. Marcussen, M. Nordsmark, F. Lundbeck, and H. von der Maase, "Presence of intratumoral neutrophils is an independent prognostic factor in localized renal cell carcinoma," Journal of Clinical Oncology, vol. 27, no. 28, pp. 4709-4717, 2009.

[33] Z. G. Fridlender, J. Sun, S. Kim et al., "Polarization of tumorassociated neutrophil phenotype by TGF- $\beta$ : 'N1' versus 'N2' TAN," Cancer Cell, vol. 16, no. 3, pp. 183-194, 2009.

[34] U. Sack, P. Stieh, and G. Geiler, "Distribution of macrophages in rheumatoid synovial membrane and its association with basic activity," Rheumatology International, vol. 13, no. 5, pp. 181-186, 1994.

[35] J. D. Ma, J. J. Zhou, D. H. Zheng et al., "Serum matrix metalloproteinase-3 as a noninvasive biomarker of histological synovitis for diagnosis of rheumatoid arthritis," Mediators of Inflammation, vol. 2014, Article ID 179284, 10 pages, 2014.

[36] J. A. Gómez-Puerta, R. Celis, M. V. Hernández et al., "Differences in synovial fluid cytokine levels but not in synovial tissue cell infiltrate between anti-citrullinated peptide/protein antibody-positive and -negative rheumatoid arthritis patients," Arthritis Research \& Therapy, vol. 15, no. 6, article R182, 2013.

[37] L. G. M. van Baarsen, M. C. Lebre, D. van der Coelen et al., "Heterogeneous expression pattern of interleukin 17A (IL-17A), IL-17F and their receptors in synovium of rheumatoid arthritis, psoriatic arthritis and osteoarthritis: possible explanation for nonresponse to anti-IL-17 therapy?" Arthritis Research \& Ther$a p y$, vol. 16, no. 4, article 426, 2014.

[38] D. Y. S. Vogel, E. J. F. Vereyken, J. E. Glim et al., "Macrophages in inflammatory multiple sclerosis lesions have an intermediate activation status," Journal of Neuroinflammation, vol. 10, article 35, 2013. 
[39] L. Schiffer, R. Bethunaickan, M. Ramanujam et al., "Activated renal macrophages are markers of disease onset and disease remission in lupus nephritis," Journal of Immunology, vol. 180, no. 3, pp. 1938-1947, 2008.

[40] R. Bethunaickan, C. C. Berthier, M. Ramanujam et al., "A unique hybrid renal mononuclear phagocyte activation phenotype in murine systemic lupus erythematosus nephritis," Journal of Immunology, vol. 186, no. 8, pp. 4994-5003, 2011.

[41] V. Juniantito, T. Izawa, T. Yuasa et al., "Immunophenotypical characterization of macrophages in rat bleomycin-induced scleroderma," Veterinary Pathology, vol. 50, no. 1, pp. 76-85, 2013.

[42] X. Yang, J. Yang, X. Xing, L. Wan, and M. Li, "Increased frequency of Th17 cells in systemic sclerosis is related to disease activity and collagen overproduction," Arthritis Research and Therapy, vol. 16, article R4, 2014.

[43] D. W. Wojkowska, P. Szpakowski, D. Ksiazek-Winiarek, M. Leszczynski, and A. Glabinski, "Interactions between neutrophils, Th17 cells, and chemokines during the initiation of experimental model of multiple sclerosis," Mediators of Inflammation, vol. 2014, Article ID 590409, 8 pages, 2014.

[44] S. P. Zehntner, C. Brickman, L. Bourbonnière, L. Remington, M. Caruso, and T. Owens, "Neutrophils that infiltrate the central nervous system regulate T cell responses," The Journal of Immunology, vol. 174, no. 8, pp. 5124-5131, 2005.

[45] S. B. Simmons, D. Liggitt, and J. M. Goverman, "Cytokineregulated neutrophil recruitment is required for brain but not spinal cord inflammation during experimental autoimmune encephalomyelitis," Journal of Immunology, vol. 193, no. 2, pp. 555-563, 2014.

[46] A. Midgley and M. W. Beresford, "Increased expression of low density granulocytes in juvenile-onset systemic lupus erythematosus patients correlates with disease activity," Lupus, 2015.

[47] I. Papandreou, A. Powell, A. L. Lim, and N. Denko, "Cellular reaction to hypoxia: sensing and responding to an adverse environment," Mutation Research/Fundamental and Molecular Mechanisms of Mutagenesis, vol. 569, no. 1-2, pp. 87-100, 2005.

[48] M. A. Rahat, H. Bitterman, and N. Lahat, "Molecular mechanisms regulating macrophage response to hypoxia," Frontiers in Immunology, vol. 2, article 45, 2011.

[49] S. B. Coffelt, R. Hughes, and C. E. Lewis, "Tumor-associated macrophages: effectors of angiogenesis and tumor progression," Biochimica et Biophysica Acta, vol. 1796, no. 1, pp. 11-18, 2009.

[50] S. R. Walmsley, E. R. Chilvers, and M. K. B. Whyte, "Hypoxia. Hypoxia, hypoxia inducible factor and myeloid cell function," Arthritis Research \& Therapy, vol. 11, no. 2, article 219, 2009.

[51] C. Strehl, M. Fangradt, U. Fearon, T. Gaber, F. Buttgereit, and D. J. Veale, "Hypoxia: how does the monocyte-macrophage system respond to changes in oxygen availability?" Journal of Leukocyte Biology, vol. 95, no. 2, pp. 233-241, 2014.

[52] C. R. Justus, E. J. Sanderlin, and L. V. Yang, "Molecular connections between cancer cell metabolism and the tumor microenvironment," International Journal of Molecular Sciences, vol. 16, no. 5, pp. 11055-11086, 2015.

[53] C. Behn, O. F. Araneda, A. J. Llanos, G. Celedón, and G. González, "Hypoxia-related lipid peroxidation: evidences, implications and approaches," Respiratory Physiology and Neurobiology, vol. 158, no. 2-3, pp. 143-150, 2007.

[54] T. Minko, Y. Wang, and V. Pozharov, "Remediation of cellular hypoxic damage by pharmacological agents," Current Pharmaceutical Design, vol. 11, no. 24, pp. 3185-3199, 2005.
[55] H. K. Eltzschig, "Targeting hypoxia-induced inflammation," Anesthesiology, vol. 114, no. 2, pp. 239-242, 2011.

[56] M. Crowther, N. J. Brown, E. T. Bishop, and C. E. Lewis, "Microenvironmental influence on macrophage regulation of angiogenesis in wounds and malignant tumors," Journal of Leukocyte Biology, vol. 70, no. 4, pp. 478-490, 2001.

[57] M. V. Blagosklonny, "Antiangiogenic therapy and tumor progression," Cancer Cell, vol. 5, no. 1, pp. 13-17, 2004.

[58] L. I. Cárdenas-Navia, D. Yu, R. D. Braun, D. M. Brizel, T. W. Secomb, and M. W. Dewhirst, "Tumor-dependent kinetics of partial pressure of oxygen fluctuations during air and oxygen breathing," Cancer Research, vol. 64, no. 17, pp. 6010-6017, 2004.

[59] O. R. Colegio, N.-Q. Chu, A. L. Szabo et al., "Functional polarization of tumour-associated macrophages by tumourderived lactic acid," Nature, vol. 513, no. 7519, pp. 559-563, 2014.

[60] P. Bergsten, J. Westerlund, P. Liss, and P.-O. Carlsson, "Primary in vivo oscillations of metabolism in the pancreas," Diabetes, vol. 51, no. 3, pp. 699-703, 2002.

[61] J. Lengfeld, T. Cutforth, and D. Agalliu, "The role of angiogenesis in the pathology of multiple sclerosis," Vascular Cell, vol. 6, article 23, 2014.

[62] A. M. Amorini, V. Nociti, A. Petzold et al., "Serum lactate as a novel potential biomarker in multiple sclerosis," Biochimica et Biophysica Acta-Molecular Basis of Disease, vol. 1842, no. 7, pp. 1137-1143, 2014.

[63] J. Liu, X. Wang, X. Yang, Q. Yan, S. Wang, and W. Han, "Investigating the role of angiogenesis in systemic lupus erythematosus," Lupus, vol. 24, no. 6, pp. 621-627, 2015.

[64] V. Liakouli, P. Cipriani, A. Marrelli, S. Alvaro, P. Ruscitti, and R. Giacomelli, "Angiogenic cytokines and growth factors in systemic sclerosis," Autoimmunity Reviews, vol. 10, no. 10, pp. 590-594, 2011.

[65] H. M. Farouk, S. H. Hamza, S. A. El Bakry et al., "Dysregulation of angiogenic homeostasis in systemic sclerosis," International Journal of Rheumatic Diseases, vol. 16, no. 4, pp. 448-454, 2013.

[66] R. D. Stout and J. Suttles, "Functional plasticity of macrophages: reversible adaptation to changing microenvironments," Journal of Leukocyte Biology, vol. 76, no. 3, pp. 509-513, 2004.

[67] R. D. Stout, S. K. Watkins, and J. Suttles, "Functional plasticity of macrophages: in situ reprogramming of tumor-associated macrophages," Journal of Leukocyte Biology, vol. 86, no. 5, pp. 1105-1109, 2009.

[68] D. M. Mosser, "The many faces of macrophage activation," Journal of Leukocyte Biology, vol. 73, no. 2, pp. 209-212, 2003.

[69] F. O. Martinez, A. Sica, A. Mantovani, and M. Locati, "Macrophage activation and polarization," Frontiers in Bioscience, vol. 13, no. 2, pp. 453-461, 2008.

[70] C. Murdoch, M. Muthana, S. B. Coffelt, and C. E. Lewis, "The role of myeloid cells in the promotion of tumour angiogenesis," Nature Reviews Cancer, vol. 8, no. 8, pp. 618-631, 2008.

[71] S. Gordon and F. O. Martinez, "Alternative activation of macrophages: mechanism and functions," Immunity, vol. 32, no. 5, pp. 593-604, 2010.

[72] D. M. Mosser and J. P. Edwards, "Exploring the full spectrum of macrophage activation," Nature Reviews Immunology, vol. 8, no. 12, pp. 958-969, 2008.

[73] B.-Z. Qian and J. W. Pollard, "Macrophage diversity enhances tumor progression and metastasis," Cell, vol. 141, no. 1, pp. 39$51,2010$.

[74] F. O. Martinez and S. Gordon, "The M1 and M2 paradigm of macrophage activation: time for reassessment," F1000Prime Reports, vol. 6, article 13, 2014. 
[75] D. I. Gabrilovich and S. Nagaraj, "Myeloid-derived suppressor cells as regulators of the immune system," Nature Reviews Immunology, vol. 9, no. 3, pp. 162-174, 2009.

[76] S. Ostrand-Rosenberg and P. Sinha, "Myeloid-derived suppressor cells: linking inflammation and cancer," Journal of Immunology, vol. 182, no. 8, pp. 4499-4506, 2009.

[77] V. Bronte, "Myeloid-derived suppressor cells in inflammation: uncovering cell subsets with enhanced immunosuppressive functions," European Journal of Immunology, vol. 39, no. 10, pp. 2670-2672, 2009.

[78] V. Bronte and P. Zanovello, "Regulation of immune responses by L-arginine metabolism," Nature Reviews Immunology, vol. 5, no. 8, pp. 641-654, 2005.

[79] G. P. Dunn, L. J. Old, and R. D. Schreiber, "The three Es of cancer immunoediting," Annual Review of Immunology, vol. 22, pp. 329-360, 2004.

[80] R. D. Schreiber, L. J. Old, and M. J. Smyth, "Cancer immunoediting: integrating immunity's roles in cancer suppression and promotion," Science, vol. 331, no. 6024, pp. 1565-1570, 2011.

[81] B.-Z. Qian, J. Li, H. Zhang et al., "CCL2 recruits inflammatory monocytes to facilitate breast-tumour metastasis," Nature, vol. 475, no. 7355, pp. 222-225, 2011.

[82] R. N. Hanna, C. Cekic, D. Sag et al., "Patrolling monocytes control tumor metastasis to the lung," Science, vol. 350, no. 6263, pp. 985-990, 2015.

[83] K. L. Wong, W. H. Yeap, J. J. Y. Tai, S. M. Ong, T. M. Dang, and S. C. Wong, "The three human monocyte subsets: implications for health and disease," Immunologic Research, vol. 53, no. 1-3, pp. 41-57, 2012.

[84] M. De Palma, C. Murdoch, M. A. Venneri, L. Naldini, and C. E. Lewis, "Tie2-expressing monocytes: regulation of tumor angiogenesis and therapeutic implications," Trends in Immunology, vol. 28, no. 12, pp. 519-524, 2007.

[85] M. Egeblad, A. J. Ewald, H. A. Askautrud et al., "Visualizing stromal cell dynamics in different tumor microenvironments by spinning disk confocal microscopy," Disease Models \& Mechanisms, vol. 1, no. 2-3, pp. 155-167, 2008.

[86] C. E. Lewis and J. W. Pollard, "Distinct role of macrophages in different tumor microenvironments," Cancer Research, vol. 66, no. 2, pp. 605-612, 2006.

[87] M. A. Venneri, M. De Palma, M. Ponzoni et al., "Identification of proangiogenic TIE2-expressing monocytes (TEMs) in human peripheral blood and cancer," Blood, vol. 109, no. 12, pp. 52765285, 2007.

[88] J. Wyckoff, W. Wang, E. Y. Lin et al., "A paracrine loop between tumor cells and macrophages is required for tumor cell migration in mammary tumors," Cancer Research, vol. 64, no. 19, pp. 7022-7029, 2004.

[89] L. Hernandez, T. Smirnova, D. Kedrin et al., “The EGF/CSF-1 paracrine invasion loop can be triggered by heregulin betal and CXCL12," Cancer Research, vol. 69, no. 7, pp. 3221-3227, 2009.

[90] A. Sica, P. Allavena, and A. Mantovani, "Cancer related inflammation: the macrophage connection," Cancer Letters, vol. 267, no. 2, pp. 204-215, 2008.

[91] S. Daniliuc, H. Bitterman, M. A. Rahat, A. Kinarty, D. Rosenzweig, and L. Nitza, "Hypoxia inactivates inducible nitric oxide synthase in mouse macrophages by disrupting its interaction with $\alpha$-actinin 4," The Journal of Immunology, vol. 171, no. 6, pp. 3225-3232, 2003.

[92] N. Lahat, M. A. Rahat, A. Kinarty, L. Weiss-Cerem, S. Pinchevski, and H. Bitterman, "Hypoxia enhances lysosomal
TNF- $\alpha$ degradation in mouse peritoneal macrophages," The American Journal of Physiology-Cell Physiology, vol. 295, no. 1, pp. C2-C12, 2008.

[93] M. A. Rahat, B. Marom, H. Bitterman, L. Weiss-Cerem, A. Kinarty, and N. Lahat, "Hypoxia reduces the output of matrix metalloproteinase-9 (MMP-9) in monocytes by inhibiting its secretion and elevating membranal association," Journal of Leukocyte Biology, vol. 79, no. 4, pp. 706-718, 2006.

[94] A. Sica, P. Larghi, A. Mancino et al., "Macrophage polarization in tumour progression," Seminars in Cancer Biology, vol. 18, no. 5, pp. 349-355, 2008.

[95] C. Maueröder, L. E. Munoz, R. A. Chaurio, M. Herrmann, G. Schett, and C. Berens, "Tumor immunotherapy: lessons from autoimmunity," Frontiers in Immunology, vol. 5, article 212, 2014.

[96] M. Walter, E. Simanovich, V. Brod, N. Lahat, H. Bitterman, and M. A. Rahat, "An epitope-specific novel anti-EMMPRIN polyclonal antibody inhibits tumor progression," OncoImmunology, 2015.

[97] M. J. Gough, N. Killeen, and A. D. Weinberg, "Targeting macrophages in the tumour environment to enhance the efficacy of $\alpha \mathrm{OX} 40$ therapy," Immunology, vol. 136, no. 4, pp. 437447, 2012.

[98] Z. G. Fridlender, A. Jassar, I. Mishalian et al., "Using macrophage activation to augment immunotherapy of established tumours," British Journal of Cancer, vol. 108, no. 6, pp. 1288-1297, 2013.

[99] T. Ueno, M. Toi, H. Saji et al., "Significance of macrophage chemoattractant protein-1 in macrophage recruitment, angiogenesis, and survival in human breast cancer," Clinical Cancer Research, vol. 6, no. 8, pp. 3282-3289, 2000.

[100] C. Chavey, F. Bibeau, S. Gourgou-Bourgade et al., "Oestrogen receptor negative breast cancers exhibit high cytokine content," Breast Cancer Research, vol. 9, no. 1, article R15, 2007.

[101] R. Kokebie, R. Aggarwal, S. Lidder et al., "The role of synovial fluid markers of catabolism and anabolism in osteoarthritis, rheumatoid arthritis and asymptomatic organ donors," Arthritis Research \& Therapy, vol. 13, no. 2, article R50, 2011.

[102] L. J. Edwards, B. Sharrack, A. Ismail, H. Tumani, and C. S. Constantinescu, "Central inflammation versus peripheral regulation in multiple sclerosis," Journal of Neurology, vol. 258, no. 8, pp. 1518-1527, 2011.

[103] V. Ramirez-Ramirez, M. A. Macias-Islas, G. G. Ortiz et al., "Efficacy of fish oil on serum of TNF $\alpha$, IL-1 $\beta$, and IL- 6 oxidative stress markers in multiple sclerosis treated with interferon beta1b," Oxidative Medicine and Cellular Longevity, vol. 2013, Article ID 709493, 8 pages, 2013.

[104] S. Garcia-Rodriguez, J.-L. Callejas-Rubio, N. Ortego-Centeno et al., "Altered AKT1 and MAPK1 gene expression on peripheral blood mononuclear cells and correlation with T-helpertranscription factors in Systemic Lupus Erythematosus patients," Mediators of Inflammation, vol. 2012, Article ID 495934, 14 pages, 2012.

[105] V. Umare, V. Pradhan, M. Nadkar et al., "Effect of proinflammatory cytokines (IL-6, TNF- $\alpha$, and IL- $1 \beta$ ) on clinical manifestations in indian SLE patients," Mediators of Inflammation, vol. 2014, Article ID 385297, 8 pages, 2014.

[106] L. Petrovic-Rackov and N. Pejnovic, "Clinical significance of IL-18, IL-15, IL-12 and TNF- $\alpha$ measurement in rheumatoid arthritis," Clinical Rheumatology, vol. 25, no. 4, pp. 448-452, 2006.

[107] A. Mouzaki, M. Rodi, N. Dimisianos et al., "Immune parameters that distinguish multiple sclerosis patients from patients 
with other neurological disorders at presentation," PLoS ONE, vol. 10, no. 8, Article ID e0135434, 2015.

[108] C. Malmeström, B. A. Andersson, S. Haghighi, and J. Lycke, "IL6 and CCL2 levels in CSF are associated with the clinical course of MS: implications for their possible immunopathogenic roles," Journal of Neuroimmunology, vol. 175, no. 1-2, pp. 176-182, 2006.

[109] A. Zickert, P. Amoudruz, Y. Sundström, J. Rönnelid, V. Malmström, and I. Gunnarsson, "IL-17 and IL-23 in lupus nephritisassociation to histopathology and response to treatment," BMC Immunology, vol. 16, article 7, 2015.

[110] E. Robak, P. Smolewski, A. Wozniacka, A. Sysa-Jedrzejowska, H. Stepień, and T. Robak, "Relationship between peripheral blood dendritic cells and cytokines involved in the pathogenesis of systemic lupus erythematosus," European Cytokine Network, vol. 15, no. 3, pp. 222-230, 2004.

[111] Z. Yin, J. Huang, W. He et al., "Serum level of eight cytokines in Han Chinese patients with systemic lupus erythematosus using multiplex fluorescent microsphere method," Central European Journal of Immunology, vol. 39, no. 2, pp. 228-235, 2014.

[112] S. Shahrara, Q. Huang, A. M. Mandelin II, and R. M. Pope, "TH17 cells in rheumatoid arthritis," Arthritis Research \& Therapy, vol. 10, no. 4, article R93, 2008.

[113] S. Desruisseau, J. Palmari, C. Giusti, S. Romain, P.-M. Martin, and Y. Berthois, "Determination of TGF $\beta$ I protein level in human primary breast cancers and its relationship with survival," British Journal of Cancer, vol. 94, no. 2, pp. 239-246, 2006.

[114] A. E. Koch, S. L. Kunkel, L. A. Harlow et al., "Enhanced production of monocyte chemoattractant protein-1 in rheumatoid arthritis," Journal of Clinical Investigation, vol. 90, no. 3, pp. 772779, 1992.

[115] J. W. Bauer, E. C. Baechler, M. Petri et al., "Elevated serum levels of interferon-regulated chemokines are biomarkers for active human systemic lupus erythematosus," PLoS Medicine, vol. 3, no. 12, article e491, 2006.

[116] H. Bartosik-Psujek and Z. Stelmasiak, "Correlations between IL-4, IL-12 levels and CCL2, CCL5 levels in serum and cerebrospinal fluid of multiple sclerosis patients," Journal of Neural Transmission, vol. 112, no. 6, pp. 797-803, 2005.

[117] E. Maae, D. A. Olsen, K. D. Steffensen et al., "Prognostic impact of placenta growth factor and vascular endothelial growth factor A in patients with breast cancer," Breast Cancer Research and Treatment, vol. 133, no. 1, pp. 257-265, 2012.

[118] H. R. Kim, K. W. Kim, B. M. Kim, M. L. Cho, and S. H. Lee, "The effect of vascular endothelial growth factor on osteoclastogenesis in rheumatoid arthritis," PLoS ONE, vol. 10, no. 4, Article ID e0124909, 2015.

[119] M. J. Bottomley, N. J. A. Webb, C. J. Watson et al., "Placenta growth factor (PlGF) induces vascular endothelial growth factor (VEGF) secretion from mononuclear cells and is coexpressed with VEGF in synovial fluid," Clinical \& Experimental Immunology, vol. 119, no. 1, pp. 182-188, 2000.

[120] E. Tham, A. W. Gielen, M. Khademi, C. Martin, and F. Piehl, "Decreased expression of VEGF-A in rat experimental autoimmune encephalomyelitis and in cerebrospinal fluid mononuclear cells from patients with multiple sclerosis," Scandinavian Journal of Immunology, vol. 64, no. 6, pp. 609-622, 2006.

[121] E. Robak, A. Sysa-Jedrzejewska, and T. Robak, "Vascular endothelial growth factor and its soluble receptors VEGFR-1 and VEGFR-2 in the serum of patients with systemic lupus erythematosus," Mediators of Inflammation, vol. 12, no. 5, pp. 293-298, 2003.
[122] B. Bielekova, M. Komori, Q. Xu, D. S. Reich, and T. Wu, "Cerebrospinal fluid IL-12p40, CXCL13 and IL-8 as a combinatorial biomarker of active intrathecal inflammation," PLOS ONE, vol. 7, no. 11, Article ID e48370, 2012.

[123] B. S. Palacios, L. Estrada-Capetillo, E. Izquierdo et al., "Macrophages from the synovium of active rheumatoid arthritis exhibit an activin a-dependent pro-inflammatory profile," The Journal of Pathology, vol. 235, no. 3, pp. 515-526, 2015.

[124] L. T. Donlin, A. Jayatilleke, E. G. Giannopoulou, G. D. Kalliolias, and L. B. Ivashkiv, "Modulation of TNF-induced macrophage polarization by synovial fibroblasts," Journal of Immunology, vol. 193, no. 5, pp. 2373-2383, 2014.

[125] L. A. N. Peferoen, D. Y. S. Vogel, K. Ummenthum et al., "Activation status of human microglia is dependent on lesion formation stage and remyelination in multiple sclerosis," Journal of Neuropathology and Experimental Neurology, vol. 74, no. 1, pp. 48-63, 2014.

[126] L. Ding, H. Gu, X. Gao, S. Xiong, and B. Zheng, "Aurora kinase a regulates $\mathrm{M} 1$ macrophage polarization and plays a role in experimental autoimmune encephalomyelitis," Inflammation, vol. 38, no. 2, pp. 800-811, 2015.

[127] W. Zhang, W. Xu, and S. Xiong, "Blockade of Notchl signaling alleviates murine lupus via blunting macrophage activation and M2b polarization," The Journal of Immunology, vol. 184, no. 11, pp. 6465-6478, 2010.

[128] J. Orme and C. Mohan, "Macrophage subpopulations in systemic lupus erythematosus," Discovery Medicine, vol. 13, no. 69, pp. 151-158, 2012.

[129] M. Manetti, "Deciphering the alternatively activated (M2) phenotype of macrophages in scleroderma," Experimental Dermatology, vol. 24, no. 8, pp. 576-578, 2015.

[130] A. Kato, M. Yutani, M. Terao et al., "Oligosaccharide modification by $\mathrm{N}$-acetylglucosaminyltransferase- $\mathrm{V}$ in macrophages are involved in pathogenesis of bleomycin-induced scleroderma," Experimental Dermatology, vol. 24, no. 8, pp. 585-590, 2015.

[131] C. C. Bain and A. M. Mowat, "The monocyte-macrophage axis in the intestine," Cellular Immunology, vol. 291, no. 1-2, pp. 4148, 2014.

[132] K. Molawi, Y. Wolf, P. K. Kandalla et al., "Progressive replacement of embryo-derived cardiac macrophages with age," The Journal of Experimental Medicine, vol. 211, no. 11, pp. 2151-2158, 2014.

[133] A. Shemer and S. Jung, "Differential roles of resident microglia and infiltrating monocytes in murine CNS autoimmunity," Seminars in Immunopathology, vol. 37, no. 6, pp. 613-623, 2015.

[134] B. A. Blok, R. J. Arts, R. van Crevel, C. S. Benn, and M. G. Netea, "Trained innate immunity as underlying mechanism for the long-term, nonspecific effects of vaccines," Journal of Leukocyte Biology, vol. 98, no. 3, pp. 347-356, 2015.

[135] F. Shojaei, M. Singh, J. D. Thompson, and N. Ferrara, "Role of Bv8 in neutrophil-dependent angiogenesis in a transgenic model of cancer progression," Proceedings of the National Academy of Sciences of the United States of America, vol. 105, no. 7, pp. 2640-2645, 2008.

[136] H. H. Yan, M. Pickup, Y. Pang et al., "Gr-1+CD11b+ myeloid cells tip the balance of immune protection to tumor promotion in the premetastatic lung," Cancer Research, vol. 70, no. 15, pp. 6139$6149,2010$.

[137] M. Kowanetz, X. Wu, J. Lee et al., "Granulocyte-colony stimulating factor promotes lung metastasis through mobilization of Ly6G+Ly6C+ granulocytes," Proceedings of the National 
Academy of Sciences of the United States of America, vol. 107, no. 50, pp. 21248-21255, 2010.

[138] Z. Granot, E. Henke, E. A. Comen, T. A. King, L. Norton, and R. Benezra, "Tumor entrained neutrophils inhibit seeding in the premetastatic lung," Cancer Cell, vol. 20, no. 3, pp. 300-314, 2011.

[139] S. Punt, J. M. Langenhoff, H. Putter, G. J. Fleuren, A. Gorter, and E. S. Jordanova, "The correlations between IL-17 vs. Th17 cells and cancer patient survival: a systematic review," OncoImmunology, vol. 4, no. 2, Article ID e984547, 2015.

[140] S. Punt, G. J. Fleuren, E. Kritikou et al., "Angels and demons: Th17 cells represent a beneficial response, while neutrophil IL-17 is associated with poor prognosis in squamous cervical cancer," OncoImmunology, vol. 4, Article ID e984539, 2015.

[141] L. Benevides, D. M. da Fonseca, P. B. Donate et al., "IL17 promotes mammary tumor progression by changing the behavior of tumor cells and eliciting tumorigenic neutrophils recruitment," Cancer Research, vol. 75, no. 18, pp. 3788-3799, 2015.

[142] S. B. Coffelt, K. Kersten, C. W. Doornebal et al., "IL-17producing gammadelta $\mathrm{T}$ cells and neutrophils conspire to promote breast cancer metastasis," Nature, vol. 522, no. 7556, pp. 345-348, 2015.

[143] R. Cascão, H. S. Rosário, M. M. Souto-Carneiro, and J. E. Fonseca, "Neutrophils in rheumatoid arthritis: more than simple final effectors," Autoimmunity Reviews, vol. 9, no. 8, pp. 531-535, 2010.

[144] J. Talbot, F. J. Bianchini, D. C. Nascimento et al., "CCR2 Expression in neutrophils plays a critical role in their migration into the joints in rheumatoid arthritis," Arthritis \& Rheumatology, vol. 67, no. 7, pp. 1751-1759, 2015.

[145] M. Katayama, K. Ohmura, N. Yukawa et al., "Neutrophils are essential as a source of IL-17 in the effector phase of arthritis," PLoS ONE, vol. 8, no. 5, Article ID e62231, 2013.

[146] M. Naegele, K. Tillack, S. Reinhardt, S. Schippling, R. Martin, and M. Sospedra, "Neutrophils in multiple sclerosis are characterized by a primed phenotype," Journal of Neuroimmunology, vol. 242, no. 1-2, pp. 60-71, 2012.

[147] M. Battaglia, "Neutrophils and type 1 autoimmune diabetes," Current Opinion in Hematology, vol. 21, no. 1, pp. 8-15, 2014.

[148] R. Bayley, K. A. Kite, H. M. McGettrick et al., "The autoimmuneassociated genetic variant PTPN22 R620W enhances neutrophil activation and function in patients with rheumatoid arthritis and healthy individuals," Annals of the Rheumatic Diseases, vol. 74, pp. 1588-1595, 2015.

[149] B. A. Kidd, P. P. Ho, O. Sharpe et al., "Epitope spreading to citrullinated antigens in mouse models of autoimmune arthritis and demyelination," Arthritis Research \& Therapy, vol. 10, no. 5, article R119, 2008.

[150] E. R. Vossenaar, S. Nijenhuis, M. M. A. Helsen et al., "Citrullination of synovial proteins in murine models of rheumatoid arthritis," Arthritis \& Rheumatism, vol. 48, no. 9, pp. 2489-2500, 2003.

[151] B. Pinegin, N. Vorobjeva, and V. Pinegin, "Neutrophil extracellular traps and their role in the development of chronic inflammation and autoimmunity," Autoimmunity Reviews, vol. 14, no. 7, pp. 633-640, 2015.

[152] M. F. Denny, S. Yalavarthi, W. Zhao et al., "A distinct subset of proinflammatory neutrophils isolated from patients with systemic lupus erythematosus induces vascular damage and synthesizes type I IFNs," The Journal of Immunology, vol. 184, pp. 3284-3297, 2010.
[153] H.-F. Pan, X.-H. Fang, G.-C. Wu et al., "Anti-neutrophil cytoplasmic antibodies in new-onset systemic lupus erythematosus and lupus nephritis," Inflammation, vol. 31, no. 4, pp. 260-265, 2008.

[154] E. Pieterse and J. van der Vlag, "Breaking immunological tolerance in systemic lupus erythematosus," Frontiers in Immunology, vol. 5, article 164, 2014.

[155] M. T. Silva and M. Correia-Neves, "Neutrophils and macrophages: the main partners of phagocyte cell systems," Frontiers in Immunology, vol. 3, article 174, 2012.

[156] C. A. Dumitru, H. Gholaman, S. Trellakis et al., "Tumorderived macrophage migration inhibitory factor modulates the biology of head and neck cancer cells via neutrophil activation," International Journal of Cancer, vol. 129, no. 4, pp. 859-869, 2011.

[157] L. L. Santos, H. Fan, P. Hall et al., "Macrophage migration inhibitory factor regulates neutrophil chemotactic responses in inflammatory arthritis in mice," Arthritis \& Rheumatism, vol. 63, no. 4, pp. 960-970, 2011.

[158] A. A. Filardy, D. R. Pires, M. P. Nunes et al., "Proinflammatory clearance of apoptotic neutrophils induces an IL-12(low)IL10(high) regulatory phenotype in macrophages," Journal of Immunology, vol. 185, no. 4, pp. 2044-2050, 2010.

[159] G. Zizzo and P. L. Cohen, "IL-17 stimulates differentiation of human anti-inflammatory macrophages and phagocytosis of apoptotic neutrophils in response to IL-10 and glucocorticoids," The Journal of Immunology, vol. 190, no. 10, pp. 5237-5246, 2013.

[160] A. N. Burska, L. Hunt, M. Boissinot et al., "Autoantibodies to posttranslational modifications in rheumatoid arthritis," Mediators of Inflammation, vol. 2014, Article ID 492873, 19 pages, 2014.

[161] R. Holmdahl, V. Malmström, and H. Burkhardt, "Autoimmune priming, tissue attack and chronic inflammation-the three stages of rheumatoid arthritis," European Journal of Immunology, vol. 44, no. 6, pp. 1593-1599, 2014.

[162] S. Yung and T. M. Chan, "Autoantibodies and resident renal cells in the pathogenesis of lupus nephritis: getting to know the unknown," Clinical and Developmental Immunology, vol. 2012, Article ID 139365, 13 pages, 2012.

[163] E. M. Tan, "Antinuclear antibodies defining autoimmunity pathways," Arthritis Research \& Therapy, vol. 16, no. 1, article 104, 2014.

[164] J. X. Shi, J. J. Qin, H. Ye, P. Wang, K. J. Wang, and J. Y. Zhang, "Tumor associated antigens or anti-TAA autoantibodies as biomarkers in the diagnosis of ovarian cancer: a systematic review with meta-analysis," Expert Review of Molecular Diagnostics, vol. 15, no. 6, pp. 829-852, 2015.

[165] S. Qi, M. Huang, H. Teng et al., "Autoantibodies to chromogranin A are potential diagnostic biomarkers for non-small cell lung cancer," Tumor Biology, vol. 36, no. 12, pp. 9979-9985, 2015.

[166] E. I. Goufman, V. N. Iakovlev, N. B. Tikhonova, and A. E. Lokshin, "Quantification of autoantibodies to plasminogen in plasma of patients with cancer," Cancer Biomarkers, vol. 15, no. 3, pp. 281-287, 2015.

[167] R. Bei, L. Masuelli, C. Palumbo, M. Modesti, and A. Modesti, "A common repertoire of autoantibodies is shared by cancer and autoimmune disease patients: inflammation in their induction and impact on tumor growth," Cancer Letters, vol. 281, no. 1, pp. $8-23,2009$.

[168] M. E. Mohammed and K. Abdelhafiz, "Autoantibodies in the sera of breast cancer patients: antinuclear and anti-double stranded DNA antibodies as example," Journal of Cancer Research and Therapeutics, vol. 11, no. 2, pp. 341-344, 2015. 
[169] G. Assmann, K. Shihadeh, V. Poeschel et al., "Prevalence of anticitrullinated protein antibodies (ACPA) in patients with diffuse large B-cell lymphoma (DLBCL): a case-control study," PLoS ONE, vol. 9, no. 2, Article ID e88177, 2014.

[170] M. Muthana, A. Giannoudis, S. D. Scott et al., "Use of macrophages to target therapeutic adenovirus to human prostate tumors," Cancer Research, vol. 71, no. 5, pp. 1805-1815, 2011.

[171] C. Twyman-Saint Victor, A. J. Rech, A. Maity et al., "Radiation and dual checkpoint blockade activate non-redundant immune mechanisms in cancer," Nature, vol. 520, no. 7547, pp. 373-377, 2015.

[172] X. Li, W. Yao, Y. Yuan et al., "Targeting of tumour-infiltrating macrophages via CCL2/CCR2 signalling as a therapeutic strategy against hepatocellular carcinoma," Gut, 2015.

[173] S. Shahrara, A. E. I. Proudfoot, C. C. Park et al., "Inhibition of monocyte chemoattractant protein-1 ameliorates rat adjuvantinduced arthritis," The Journal of Immunology, vol. 180, no. 5, pp. 3447-3456, 2008.

[174] S. A. Chalmers, V. Chitu, L. C. Herlitz, R. Sahu, E. R. Stanley, and C. Putterman, "Macrophage depletion ameliorates nephritis induced by pathogenic antibodies," Journal of Autoimmunity, vol. 57, pp. 42-52, 2015.

[175] A. Inoue, H. Hasegawa, M. Kohno et al., "Antagonist of fractalkine (CX3CL1) delays the initiation and ameliorates the progression of lupus nephritis in MRL/lpr mice," Arthritis \& Rheumatism, vol. 52, no. 5, pp. 1522-1533, 2005.

[176] E. M. Bekes, B. Schweighofer, T. A. Kupriyanova et al., “Tumorrecruited neutrophils and neutrophil TIMP-free MMP-9 regulate coordinately the levels of tumor angiogenesis and efficiency of malignant cell intravasation," The American Journal of Pathology, vol. 179, no. 3, pp. 1455-1470, 2011.

[177] H. Verbeke, S. Struyf, N. Berghmans et al., "Isotypic neutralizing antibodies against mouse GCP-2/CXCL6 inhibit melanoma growth and metastasis," Cancer Letters, vol. 302, no. 1, pp. 54-62, 2011.

[178] X. G. Wang, Q. Meng, F. M. Qi, and Q. F. Yang, "Blocking TGFbeta inhibits breast cancer cell invasiveness via ERK/S100A4 signal," European Review for Medical and Pharmacological Sciences, vol. 18, pp. 3844-3853, 2014.

[179] K. Garrison, T. Hahn, W.-C. Lee, L. E. Ling, A. D. Weinberg, and E. T. Akporiaye, "The small molecule TGF- $\beta$ signaling inhibitor SM16 synergizes with agonistic OX40 antibody to suppress established mammary tumors and reduce spontaneous metastasis," Cancer Immunology, Immunotherapy, vol. 61, no. 4, pp. 511-521, 2012.

[180] M. Uhl, S. Aulwurm, J. Wischhusen et al., "SD-208, a novel transforming growth factor $\beta$ receptor I kinase inhibitor, inhibits growth and invasiveness and enhances immunogenicity of murine and human glioma cells in vitro and in vivo," Cancer Research, vol. 64, no. 21, pp. 7954-7961, 2004.

[181] B. Zhang, S. K. Halder, S. Zhang, and P. K. Datta, “Targeting transforming growth factor-beta signaling in liver metastasis of colon cancer," Cancer Letters, vol. 277, no. 1, pp. 114-120, 2009. 


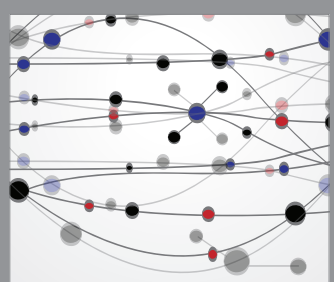

The Scientific World Journal
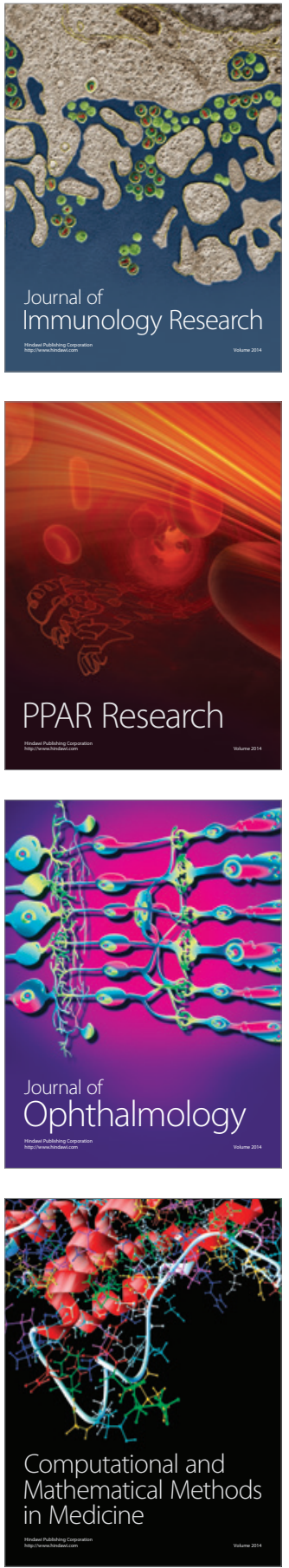

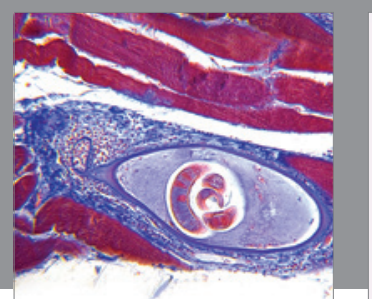

Gastroenterology Research and Practice

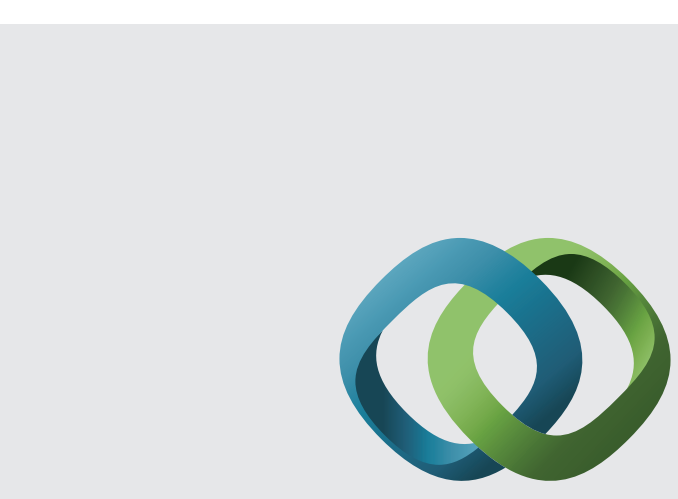

\section{Hindawi}

Submit your manuscripts at

http://www.hindawi.com
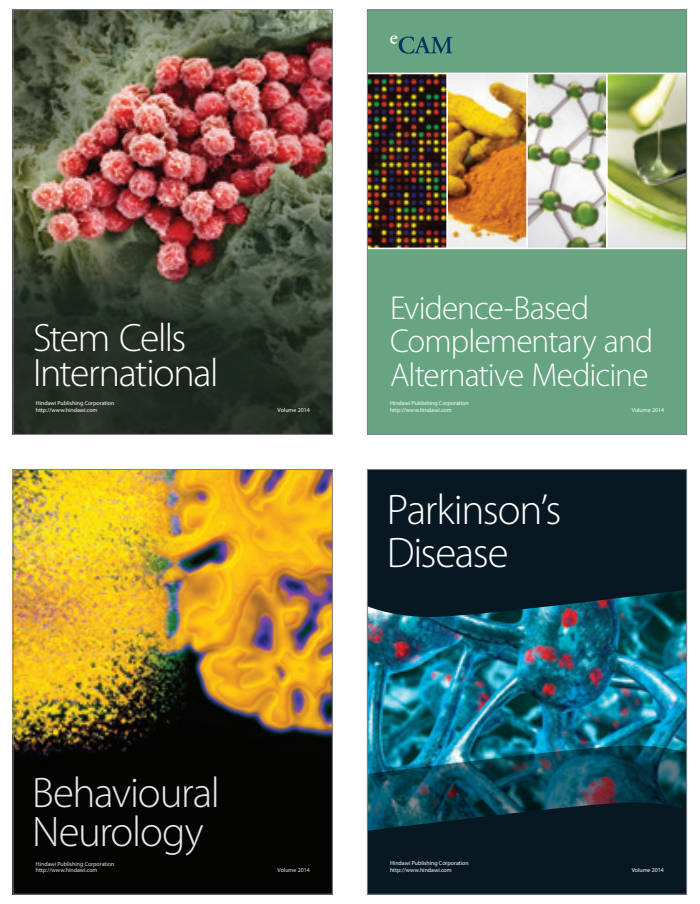
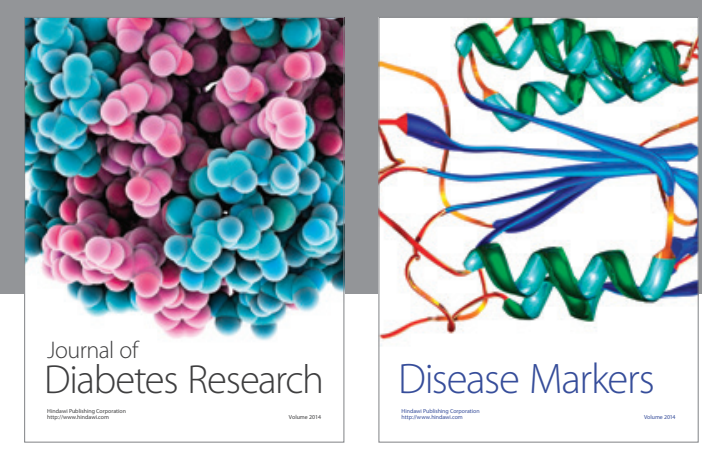

Disease Markers
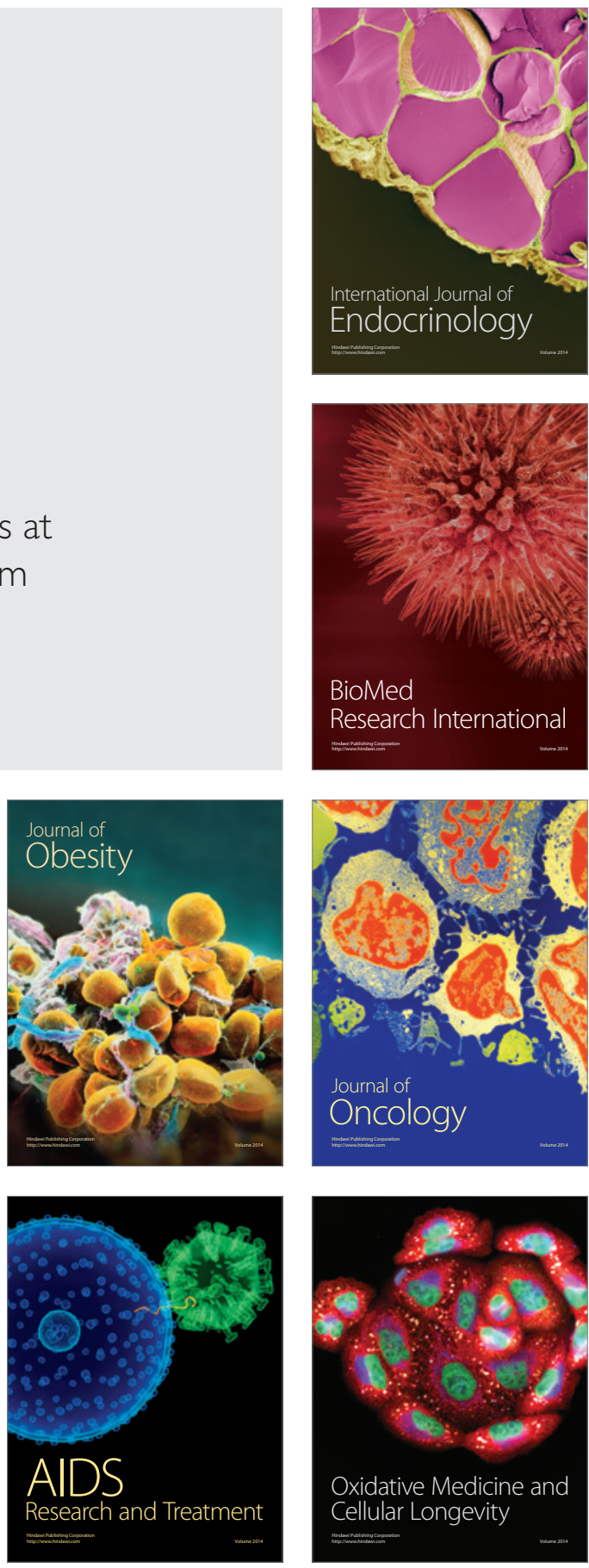